\title{
Comparison and Optimization of Operational Parameters in Removal of Heavy Metal Ions from Aqueous Solutions by Low-Cost Adsorbents
}

\author{
Aziz Babapoor ${ }^{10},{ }^{1}$ Omid Rafiei, ${ }^{1}$ Yousef Mousavi, ${ }^{1}$ Mohammad Mehdi Azizi, ${ }^{2}$ \\ Meysam Paar, ${ }^{1}$ and Ayat Nuri ${ }^{3}$ \\ ${ }^{1}$ Department of Chemical Engineering, University of Mohaghegh Ardabili, P.O. Box 179, Ardabil, Iran \\ ${ }^{2}$ Department of Chemistry and Biochemistry, University of Texas at Arlington, Arlington, TX, USA \\ ${ }^{3}$ Department of Applied Chemistry, Faculty of Science, University of Mohaghegh Ardabili, Ardabil, Iran \\ Correspondence should be addressed to Aziz Babapoor; babapoor@uma.ac.ir
}

Received 7 September 2021; Revised 26 November 2021; Accepted 5 December 2021; Published 30 January 2022

Academic Editor: Witold Kwapiński

Copyright ( $(2022$ Aziz Babapoor et al. This is an open access article distributed under the Creative Commons Attribution License, which permits unrestricted use, distribution, and reproduction in any medium, provided the original work is properly cited.

\begin{abstract}
Removal of heavy metal ions such as cadmium, lead, chromium, and iron from industrial wastewater is one of the most critical environmental problems. In this research, natural and low-cost adsorbents like the tangerine peel, bovine gut, tea waste, and sunflower seed hull were used for adsorption of heavy metals, such as chromium and iron, from contaminated solutions. The effects of environmental factors such as contact time, $\mathrm{pH}$, the amount of adsorbent dose, and the initial concentration of metal ions in synthetic solution were investigated to obtain optimal conditions for the adsorption of heavy metal ions. For separation of chromium metal ion from aqueous solution, tea waste, tangerine peel, bovine gut, and sunflower seeds hull showed adsorption capacity of $85 \%, 51 \%, 46 \%$, and $34 \%$, respectively, while for the adsorption of iron (III), the adsorption capacities of tea waste, bovine gut, tangerine peel, and sunflower seeds hull were $96 \%, 96 \%$, and $87 \%$, respectively. The adsorption isotherms were in decent correlation with the Langmuir and Freundlich isotherm models. The adsorption kinetics of iron and chromium has a proper validation with the pseudo-second-order kinetic model. The BET and FTIR analyses were also reported to investigate the adsorption properties. This study suggests these adsorbents as low-cost and economical materials for the adsorption of chromium and iron ions with a high adsorption rate.
\end{abstract}

\section{Introduction}

Nowadays, with the development of industries and increasing the population, especially in developing countries, the release of heavy metals by the wastewater of these industries into the environment is one of the most critical environmental problems. Heavy metals have atomic weights between 63.5 and 200.6, and generally, the specific gravity of these elements is larger than five [1]. Different heavy metals, including but not limited to copper, zinc, mercury, lead, cadmium, iron, and chromium elements, enter the environment by industrial wastewater. Many industries such as steel, refining ores, batteries, mining, pesticides, tanneries, fertilizer, and paper industries are among the most important emission sources of these pollutants [2-5]. Unlike organic pollutants, these elements are not biodegradable and can quickly accumulate in the body of living organisms $[6,7]$. Heavy metals are present naturally in rocks and ore minerals. Therefore, a range of various concentrations of these elements can be found in water, soils, and living organisms. Excessive accumulation of heavy metals in the human body can hurt the functioning of various organs such as the liver and kidney, and it can be one of the causes of tumors [8]. Table 1 shows the typical poisoning symptoms and maximum contamination level (MCL) amount of the most common heavy metals $[9,10]$.

Various international regulatory agencies such as the World Health Organization (WHO) have defined the 
TABLE 1: The MCL standards for the most hazardous heavy metals.

\begin{tabular}{lcc}
\hline Heavy metal & Toxicities & MCL (mg/L) \\
\hline Cadmium & Kidney damage, renal disorder, human carcinogen & 0.01000 \\
Nickel & Dermatitis, nausea, chronic asthma, coughing, human carcinogen & 0.20000 \\
Zinc & Depression, lethargy, neurological signs, and increased thirst & 0.80000 \\
Mercury & Rheumatoid arthritis, and diseases of the kidneys, circulatory system, and nervous system & 0.00003 \\
Lead & Damage the fetal brain, diseases of the kidneys, circulatory system, and nervous system & 0.00600 \\
Arsenic & Skin manifestations, visceral cancers, vascular disease & 0.05000 \\
Chromium & Headache, diarrhea, nausea, vomiting, carcinogenic & 0.05000 \\
Copper & Liver damage, Wilson disease, insomnia & 0.02500 \\
\hline
\end{tabular}

maximum permitted levels of heavy metals in the industrial wastewaters [11]. Many conventional methods such as chemical precipitation, coagulation and flocculation, adsorption, electrochemical treatment, flotation, ion exchange, and membrane filtration are used to remove metal ions from aqueous solutions $[12,13]$. Each of these separation techniques has its own pros and cons. Therefore, choosing an effective, economical, simple, and affordable method is very important. Among these methods, the adsorption method is more recognized as an economical and effective method for removing heavy metals from contaminated solutions [14]. The adsorption process is generally consisting of a mass transfer process, in such a manner that a substance is transferred from the fluid phase (liquid or gas) to the surface of a solid phase and interacts via either physical forces, ion exchange, or chemical bonding $[15,16]$. In addition, because the adsorption process in some cases is reversible, adsorbents can be regenerated by the appropriate desorption process. Also, when the concentration of metal ions in the contaminated solution is low, the adsorption method is very suitable for removing these elements [17].

Using activated carbon is one of the most important methods of adsorption of metal ions from wastewater [16]. Activated carbon has many advantages due to its high volume of micropore and mesopore cavities and, as a result, high effective surface area [18]. Many researchers used this method for the adsorption of metal ions from wastewater $[19,20]$. Despite many advantages, the loss of activated carbon during the regeneration and high costs limits its industrial applications [7, 10, 21].

In the last three decades, the removal of metal ions from aqueous media with renewable organic substances has attracted more attention [22-24]. Agricultural wastes, natural substances, industrial by-products, etc. can be applied for the removal of metal ions in contaminated aqueous solutions. Some of the materials that are extracted from agricultural waste can be applied as a low-cost natural adsorbent for the adsorption and recovery of heavy metals [25-28]. Having high efficiency, low cost, low chemical and biological sludge, and the possibility of metal ions recovery are the most important advantages of this method [29]. Using agricultural adsorbents as inexpensive, abundant, and available materials to remove heavy metal ions has attracted much attention. In addition, combustion and incorrect disposal of agricultural waste materials can cause serious problems. Therefore, many low-cost adsorbents such as apple wastes [30], peanut skins [31], rice hulls [32], and hazelnut skin [33] have been used extensively for adsorption of heavy metal ions from wastewater. Babel and Kurniawan used low-cost substances like chitosan, zeolite, etc. to eliminate heavy metals instead of using activated carbon [34].

Amarasinghe and Williams compared the absorption of lead and copper ions by tea waste with other commonly available alternative adsorbents. They performed some experiments to determine the factors influencing the adsorption and kinetics of the process. The fixed-bed column test was performed to evaluate the practical application and success curves [35].

Aydin et al. studied the utilization of cheap adsorbents as an alternative to common expensive metal removal methods. The separation of copper (II) from the aqueous media was investigated by various adsorbents such as lentils, wheat, and rice shells. The equilibrium adsorption rate was defined as a function of initial concentration, solution temperature, $\mathrm{pH}$, and contact time. Copper (II) adsorption isotherms were in decent correlation with the Langmuir and Freundlich models. They also calculated thermodynamic parameters such as free energy (DG0), enthalpy (DH0), and entropy changes (DS0) to absorb copper (II) to forecast the behavior of the adsorption process and examined adsorption process control factors [36]. Wang et al. removed manganese and metal ions (such as $\mathrm{Fe}_{3} \mathrm{O}_{4}$, metal wool, magnesium ion, $\mathrm{Fe}_{2} \mathrm{O}_{3}$, copper, zinc, and alum particles) from aqueous solutions by low-cost adsorbents. The experiments were done at various $\mathrm{pH}$ values and metal concentrations. The effect of solvent $\mathrm{pH}$ on metal uptake was significant in the removal of $\mathrm{Fe}_{2} \mathrm{O}_{3}$ and $\mathrm{Fe}_{3} \mathrm{O}_{4}$ and they concluded that steel wool and magnesium bullets were better adsorbents [12].

In this study, four cheap adsorbents including tea waste, tangerine peel, bovine gut, and sunflower seed hull were used to measure and optimize adsorption conditions to remove iron and chromium ions from the aqueous solutions. Annually, large amounts of these substances are released into the environment. Although these materials are organic and they do not pose any danger to the environment, their annual rate of production and disposal is very high. For this reason, in this study, we used these four substances as inexpensive adsorbents to absorb metal ions from wastes. Effects of different parameters such as $\mathrm{pH}$ of the solution containing heavy metals, contact time, adsorbent/ion, and primary concentration of heavy metals in aqueous media were investigated. The Langmuir and Freundlich adsorption isotherms have been studied to analyze isotherm data to 
specify the adsorption capacity of these materials. Also, the kinetics of adsorption were investigated and compared with pseudo-first and pseudo-second-order models.

\section{Materials and Methods}

2.1. Low-Cost Adsorbent. Tea is the name of a fragrant beverage obtained from brewing the processed leaves of the Camellia sinensis plant. It is the second most consumed beverage globally after water. According to the International Tea Committee report in 2020, global tea production reached about 6.1 million tons in 2019. On the other hand, some products that are derived from tea, such as cosmetics, tea tree oil, foods, and beverages based on tea extract, food coloring, etc. have also become popular. Increasing the consumption of tea and its by-products increases the production of tea pulp. India, China, Sri Lanka, and Kenya are the largest producers of tea in the world. For example, India has a production of 857,000 tons of tea per year and has about $27.4 \%$ of the total annual production in the world. During the tea processing process in the factory, about 190,400 tons of tea waste is produced. In India, a small portion of this waste is used as animal feed, compost, and caffeine production, and a huge volume of waste, which contains various components of the tea plant, is disposed of in inappropriate ways which cause environmental problems [37]. In this regard, many studies have been done to convert tea waste into a valuable source for energy production [38], adsorbents for wastewater treatment [39], medicinal antioxidants such as caffeine [40], etc.

Citrus is one of the most abundant and widespread agricultural crops in the world. China, Brazil, and India are the largest producers of citrus in the world. According to the FAO, citrus production in the world was about 124 million tons in 2016. Citrus fruits are a rich source of vitamins, fiber, and antioxidants including ascorbic acid, flavonoids, limonoids, and phenolic compounds that are very useful for human health [41]. Tangerine is one of the fruits of this group, which has the largest share of the citrus market after orange. In 2019, the world's tangerine production was 31.7 million tons [42]. About a third of the total volume of citrus is converted into juice in factories. In these factories, citrus peel, which contains a large volume, is usually disposed of improperly and causes environmental problems [43]. Accordingly, various studies have been conducted to reduce the release of citrus residues into the environment. The use of citrus peels, including tangerines, to adsorption of heavy metals [44], flavorings [45], and biofuels [46], has been considered in the pharmaceutical and health industries [47].

Sunflower seeds are one of the largest sources of vegetable oil production in the world after soybean, rapeseed, cotton, and peanuts. About 25.8 million tons of sunflower seeds are produced in the world, where a large part of it is dedicated to oil extraction. The sunflower seed oil volume is about $8.2 \%$ of the total edible oils produced globally (about 107 tons per year) [48]. In the process of extracting oil from sunflower seeds, about $50 \%$ of the weight of sunflower seeds is converted into waste $[49,50]$. Sunflower hull has a low economic value and every year the oil-producing industries discharge a large part of it into the environment and only a small part of it is used as a source of energy and animal feed. Recent studies on these wastes have shown that the sunflower seed hull can be used as an inexpensive adsorbent to the adsorption of dyes and heavy metal ions from wastewater [48, 49]. Sunflower seed skin contains cellulose, lignin, carboxylic acid, and hemicellulose with functional groups $\mathrm{O}-\mathrm{H}, \mathrm{C}-\mathrm{O}$, and $\mathrm{C}=\mathrm{C}$, which provides suitable binding sites [51].

Large amounts of red meat are produced annually as an important source of protein around the world. Cow intestine is one of the waste products of slaughterhouses, which has a very high volume and their disposal is associated with many problems. In this study, for the first time, the cow intestine was used as an adsorbent to remove heavy metals.

2.2. Materials. Chemical materials used in this study include iron (III) nitrate, potassium dichromate, hydrochloric acid, and sodium hydroxide which were provided by Merck. Also, the low-cost adsorbents such as tea waste, tangerine peel, bovine gut, and sunflower seed hull were prepared from the village markets. Tables 2 and 3 show the characterization of potassium dichromate and iron (III) nitrate.

2.3. Laboratory Instruments. Equipment and devices used in this study include lab mill, sieve with a mesh size of 65 , analytical balance, $\mathrm{pH}$ meter, shaker, centrifuge, spectrophotometer, Brunauer-Emmett-Teller (BET) Analyzer to measure the porosity and adsorption effective levels, Fourier transform infrared spectroscopy (FTIR), and scanning electron microscope (SEM).

In order to pulverize the desired adsorbents after the drying process, a laboratory milling machine was used. Sieve mesh 65 was used to screen the adsorbent grains after pulverizing the adsorbents by the milling process.

The masses of all solid materials were measured by the analytical balance with an accuracy of $1 \mathrm{~g}$, and a digital $\mathrm{pH}$ meter was used to adjust the $\mathrm{pH}$ of the solutions. In this study, a shaker device was used to shake the solution, which was used for contaminated water samples at an average speed of $150 \mathrm{rpm}$. The centrifuge device was also used to filter and separate the particles from the solvent in the solution. The maximum rotation speed of this device was $5000 \mathrm{rpm}$.

A spectrophotometer was used to measure the residual concentrations of chromium and iron ions after contact with the adsorbent. The concentration of chromium and iron ions was measured by spectrophotometry, and the percentage of metal ion removal is obtained by using the following equation:

$$
S=\left(\frac{\mathrm{Ci}-\mathrm{Cf}}{\mathrm{Ci}}\right) \times 100 .
$$

In this equation, $S$ is the percentage of metal ions removed, $\mathrm{Ci}$ is the initial concentration of metal ions in solution in $\mathrm{mg} / \mathrm{L}$, and $\mathrm{Cf}$ is the final concentration of metal ions in solution after contact with the adsorbent. 
TABLE 2: Characterization of potassium dichromate.

\begin{tabular}{lc}
\hline Heavy metal & Iron (III) \\
\hline $\begin{array}{l}\text { Equivalent } \\
\text { name }\end{array}$ & $\begin{array}{c}\text { Bichromate of potash, dipotassium dichromate, } \\
\text { potassium bichromate }\end{array}$ \\
Chemical & $\mathrm{K}_{2} \mathrm{Cr}_{2} \mathrm{O}_{4}$ \\
formula & 294.185 \\
Molecular mass & $5-157-231$ \\
EINECS & \\
\hline
\end{tabular}

TABLE 3: Characterization of iron (III) nitrate.

\begin{tabular}{lc}
\hline Heavy metal & Iron (III) \\
\hline Equivalent name & Nitric acid iron $(3+)$ salt, ferric nitrate \\
Chemical formula & $\mathrm{Fe}\left(\mathrm{NO}_{3}\right)_{3}$ \\
Molecular mass & 241.86 \\
EINECS & $5-899-233$ \\
\hline
\end{tabular}

The Brunauer-Emmett-Teller (BET) method is generally used to measure the specific surface area of the adsorbent on the basis of gas adsorption analysis. The principles of this device are based on measuring the absorption and desorption of neutral gas such as nitrogen at a constant temperature $(77 \mathrm{~K})$ on the surface of the adsorbent. In this method, after placing the sample in the liquid nitrogen tank, the volume of adsorbed nitrogen gas by the sample is calculated by gradually increasing the nitrogen gas pressure at each stage. Then, with the gradual decrease of gas pressure, the amount of desorption is measured, and finally, the graph of the volume of adsorbed and desorbed nitrogen gas by the sample is drawn based on the relative pressure at a constant temperature, where the effective surface area of the material is extracted from these diagrams. BET diagram is also called adsorption and desorption isotherm.

Fourier transform infrared spectroscopy (FTIR) is the most suitable method for identifying organic and inorganic materials as well as different functional groups in materials and can be used to analyze solids, liquids, and gases. FTIR uses mathematical methods (Fourier transform) to convert raw data into real spectra. Materials absorb light at different ranges of infrared wavelengths, and the FTIR method uses this same feature to detect the molecular structure of different compounds by obtaining the infrared spectrum absorbed by the sample in terms of wavelength. When a sample is exposed to infrared radiation, the absorbed spectrum leads to the excitation of molecules and vibrational transitions. The absorbed wavelength is a function of the energy difference between the two vibrational levels. Therefore, according to the absorbed wavelengths, the vibrational levels and molecular structure of the material can be understood.

A scanning electron microscope (SEM) is a device used to examine the surface morphology of adsorbents and the particle size of prepared powders. Electron microscopes can provide images from surfaces at 10 to $100,000 \mathrm{x}$ magnification. In scanning electron microscopy, the focused electron beam collisions with sample surface atoms and revelation of secondary electrons due to ionization of light atoms at the sample surface as well as return electrons due to elastic collisions with nuclei of heavy atoms on the sample surface as well as X-ray produced spectroscopy can be reached images and spectra that represent valuable information of the surface constituent atoms of the sample and is considered as an effective tool in a wide range of research on material recognition and imaging of the sample in nanometer dimensions.

2.4. Adsorbent Preparation. The low-cost adsorbents used in this study include tea waste, tangerine peel, bovine gut, and sunflower seed hull. Figure 1 shows the images of these adsorbents. The adsorbents were washed and dried naturally by exposure to sunlight. Then, dried adsorbents were ground and then passed through sieves with mesh sizes of 65 . These materials were used as the adsorbent to remove heavy metal ions from wastewater without using chemical or physical treatment.

2.5. Metal Ions Solution Preparation. In this study, potassium dichromate and iron nitrate solutions were used to simulate wastewater containing heavy metals. The equations of (2) and (3) are used to determine the standard solution concentration of iron and chromium ions, respectively. For example, according to equation (2), $4.331 \mathrm{~g}$ of solid iron (III) nitrate $\left(\mathrm{Fe}\left(\mathrm{NO}_{3}\right)_{3}\right)$ powder is dissolved in $1000 \mathrm{ml}$ of distilled water to obtain an iron ion solution with a concentration of $1000 \mathrm{mg} / \mathrm{L}$.

$$
\begin{gathered}
\mathrm{Fe}\left(\mathrm{NO}_{3}\right)_{3}(g)=\frac{\left(M_{w\left(\mathrm{Fe}\left(\mathrm{NO}_{3}\right)\right)_{3}}\right)}{M_{(\mathrm{Fe})}}, \\
\mathrm{K}_{2} \mathrm{Cr}_{2} \mathrm{O}_{7}(g)=\frac{\left(M_{w(\mathrm{~K} 2 \mathrm{Cr} 2 \mathrm{O})}\right)}{M_{(\mathrm{Cr})} \times 2} .
\end{gathered}
$$

In these relations, $M_{W}$ is the molecular mass $(\mathrm{g} / \mathrm{mol})$ and $M$ is the atomic mass $(\mathrm{g} / \mathrm{mol})$. According to the equation of (4), different concentrations of iron and chromium ion solution were prepared using standard solution dilution.

$$
M_{1} V_{1}=M_{2} V_{2} .
$$

In equation (4), $M_{1}$ is the concentration of the standard solution $(1000 \mathrm{mg} / \mathrm{L}), M_{2}$ is the concentration of the desired solution $(\mathrm{mg} / \mathrm{L}), V_{1}$ is the volume of the standard solution used $(\mathrm{ml})$, and $V_{2}$ is the required volume of the desired solution $(\mathrm{ml})$.

It should be noted that the adsorption capacity is a thermodynamic parameter but the adsorption efficiency is a kinetic parameter. In equation (5), $q$ is adsorption capacity and in equation (6), and $R$ is adsorption efficiency.

$$
\begin{aligned}
& q=\frac{\left(C_{i}-C_{f}\right) \times T}{W_{g}}, \\
& R=\frac{C_{i}-C_{f}}{C_{i}} \times 100 .
\end{aligned}
$$

\section{Results and Discussion}

In order to optimize the conditions for removal of heavy metals with low-cost adsorbents, chromium and 


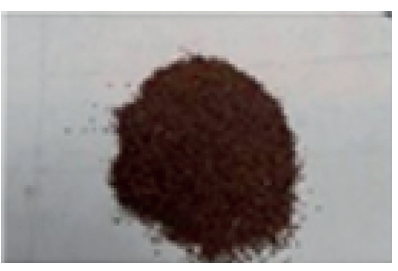

(a)

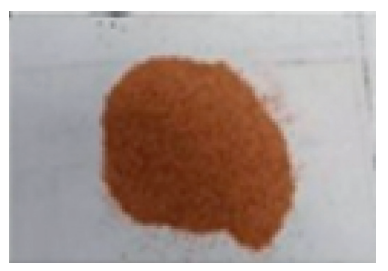

(b)

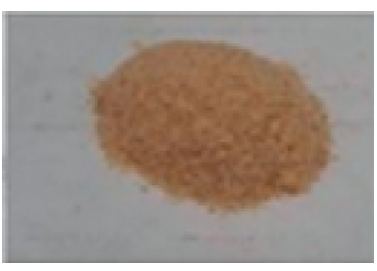

(c)

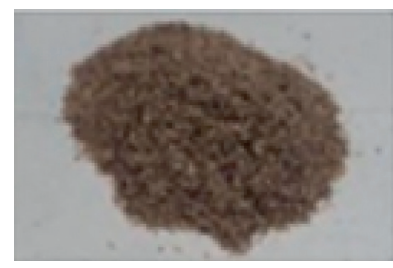

(d)

Figure 1: Images of adsorbents (a) tea waste, (b) tangerine peel, (c) bovine gut, and (d) sunflower seed hull.

iron metal ions were extracted from the wastewater by tea waste, tangerine peel, bovine gut, and sunflower seed hull. The effects of $\mathrm{pH}$, the dose of adsorbents, adsorption time, and initial metal ions concentrations were investigated.

3.1. Optimal $\mathrm{pH}$ for Adsorption of Chromium. The $\mathrm{pH}$ value of the solution is an effective parameter in the adsorption process [52]. Based on many studies that have been done to remove the chromium by various adsorbents, the adsorption amount of chromium by the different adsorbents is a function of $\mathrm{pH}$, and by increasing the $\mathrm{pH}$ from 2 to 8 , the adsorption amount significantly decreases [53]. By lowering the $\mathrm{pH}$ in the adsorption process, in addition to hydrolysis of water molecules, the reduction of hexavalent chromium to trivalent chromium also occurs. Trivalent chromium ions at these $\mathrm{pH}$ ranges are either not adsorbed or poorly adsorbed. Therefore, $\mathrm{pH}$ has the most significant effect on the adsorption of chromic ions. In acidic environments, the adsorbed substrate surface gains a positive charge by $\mathrm{H}^{+}$ ions, and on the other hand, hexavalent chromium is present in these $\mathrm{pHs}$ in the form of anionic species, which results in better adsorption of chromium at the acidic pHs. In all tests, the sample volume was $50 \mathrm{~mL}$.

In order to determine the optimum $\mathrm{pH}$ (other parameters were kept constant), initial chromium concentration is $100 \mathrm{ppm}$, adsorbent dose is $0.1 \mathrm{~g}$, and contact time is $24 \mathrm{hr}$. The trends of chromium adsorption by four different adsorbents at different $\mathrm{pHs}$ are shown in Figure 2(a). As depicted in Figure 2(a), the results show the adsorption rate of chromium ions mostly depends on the $\mathrm{pH}$ value of the solution. For all the adsorbents used in the chromium removal test, the optimum $\mathrm{pH}$ is 2 . Pehlivan and Altun removed hexavalent chromium using almond, hazelnut, and walnut skin [53]. The results of this study showed that the adsorption rate strongly depends on the $\mathrm{pH}$ value of the solution, and the maximum amount of chromium adsorption occurs at $\mathrm{pH}=2$. This phenomenon occurs usually because, at low $\mathrm{pH}$, the adsorbent surfaces interact with hydronium ions, which leads to the interaction between dichromate and adsorbent [52]. Additionally, at low $\mathrm{pH}$ values, the hexavalent chromium is predominantly in the form of hydrogen chromate anions, which in such conditions will replace the hydroxide ions in the active adsorbent [54]. Dave et al. and Nigam et al. investigated the effect of $\mathrm{pH}$ on the adsorption of chromium (VI) ions from contaminated solutions with tea waste. They also concluded that the percentage of chromium ion removal decreases with increasing $\mathrm{pH}$, which is consistent with the results obtained in this study $[55,56]$.

3.2. Optimal $p H$ for Iron Adsorption. IThe results of the experiment to determine the optimum $\mathrm{pH}$ value for the adsorption of iron are shown in Figure 2(b). As shown in Figure 2(b), the maximum amount of adsorbed iron ion was in the $\mathrm{pH}$ range of 3 to 6 , which can be expressed based on the adsorbent surface charge and the percentage of hydrogen ions in the solution. In other words, at pHs below three, the concentration of $\mathrm{H}^{+}$ions in the environment is high. Therefore, the surface of the adsorbent poses a positive charge. Competition between $\mathrm{H}^{+}$ions and metal ions, on the one hand, and repulsions between metal ions and positively charged adsorbents particles, on the other hand, decrease the adsorption. The adsorption amount of iron ions at higher pHs decreases due to the increase of $\mathrm{OH}^{-}$ions in the environment of solution and the formation of metal hydroxide precipitates. Therefore, the experiment was ignored at higher $\mathrm{pH}$ values [57].

In this part of the experiment, the concentration of the contaminant is $100 \mathrm{ppm}$, the contact time was $24 \mathrm{hr}$, and the adsorbent amount for the tea waste and sunflower seed hull was $0.1 \mathrm{~g}$, and that for the tangerine peel and bovine gut was $0.05 \mathrm{~g}$. Because the adsorption amount of iron ions by the adsorbents of tangerine peel and bovine gut was very higher at low $\mathrm{pH}$ values, therefore, a lower ratio of these adsorbents was selected compared with tea waste and sunflower seed hull.

It can be seen from Figure 2(b) that the adsorption of iron by the four adsorbents greatly depends on the $\mathrm{pH}$ of the solution and the largest adsorption rate was observed at a $\mathrm{pH}$ of 4 .

3.3. Optimal Contact Time. Another effective factor in the adsorption of heavy metals ions is the contact time. Therefore, the optimal contact time at which the metal adsorption rate is the highest should be obtained. The previously optimized $\mathrm{pH}$ values of 2 and 4 for chromium and iron ions were considered. Also, the adsorbent amount for removal of chromium for all four adsorbents was $0.1 \mathrm{~g}$, but for the adsorption of iron, the adsorbent amount of tea waste and sunflower seeds hull was $0.1 \mathrm{~g}$, and that for the adsorption of tangerine peel and bovine gut was $0.05 \mathrm{~g}$. The initial metal ion concentration was selected at $100 \mathrm{ppm}$ for both pollutants. The results of the experiment to determine 


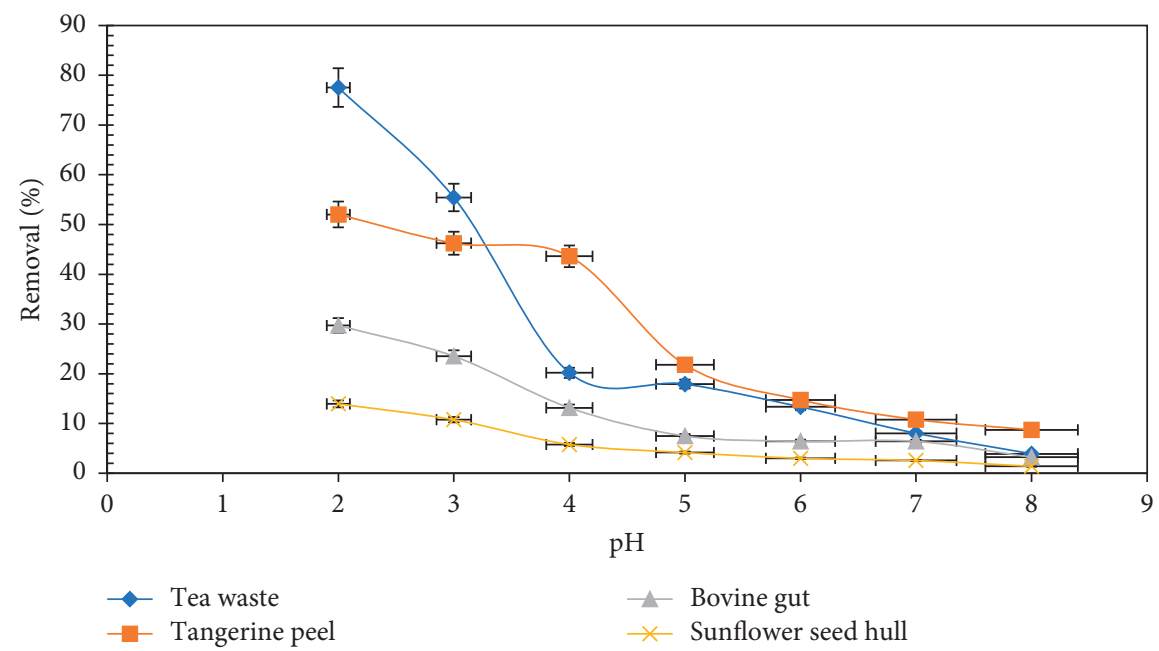

(a)

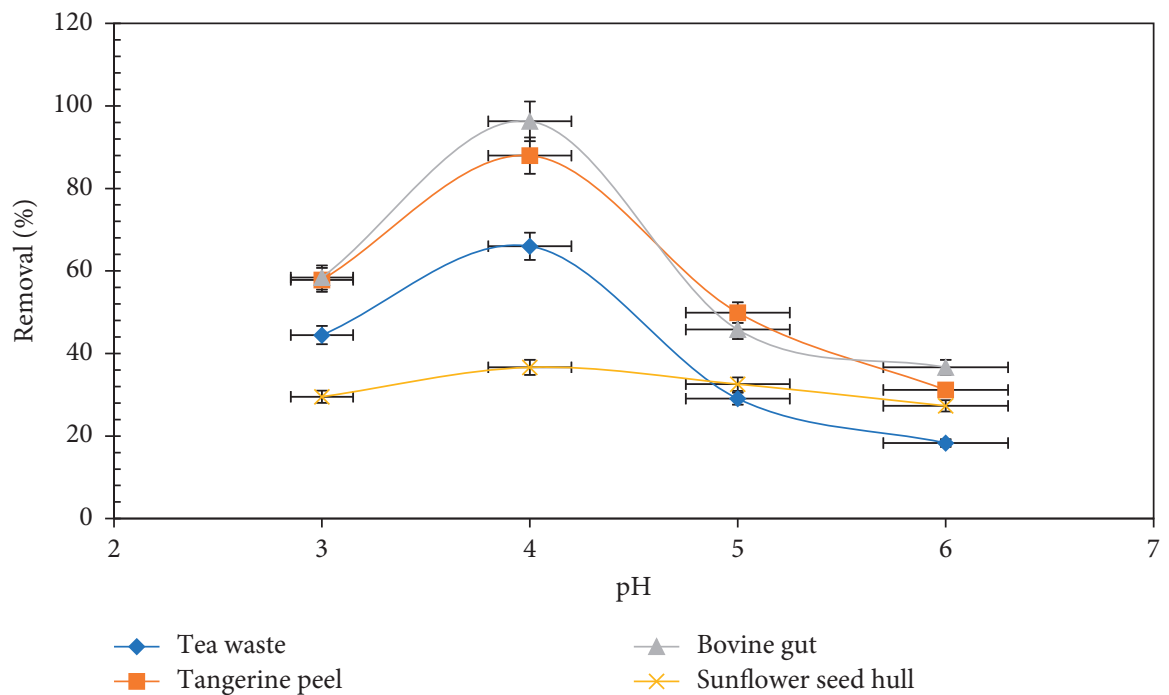

(b)

Figure 2: Effect of $\mathrm{pH}$ changes on (a) chromium adsorption rate and (b) iron adsorption rate.

the optimum time for chromium and iron adsorption are shown in Figures 3(a) and 3(b), respectively.

The adsorption has an upward trend in the early times, but due to the decrease in the number of active sites, this trend gradually slows down, and eventually, it returns to a fixed value. Obviously, with increasing the contact time due to the increased chance of collision between metal ions and adsorbent particles, the amount of adsorption is increased, and after reaching a specific time, the amount of adsorption is fixed, and contact between the metal ions with the adsorbent after the equilibrium conditions will not show a tangible effect on the rate of adsorption. Dave et al. and Nigam et al. investigated the effect of the duration of contact of the tea pulp adsorbent on the adsorption performance of chromium ions from the contaminated solution. It has been observed that the percentage of removal of chromium ions from the contaminated solution increases with increasing contact time but remains constant after a certain period of time. The results obtained in this study are in good agreement with the results obtained in the study of Dave et al. and Nigam et al. [55, 56]

3.4. Optimum Concentration of Adsorbent. One of the crucial parameters in the adsorption of heavy metals by low-cost adsorbents is the ratio of adsorbents to the number of contaminant ions. This part of the experiments was carried out by considering the constant values for the other effective parameters to determine the optimum concentration of adsorbents. These experiments were performed separately for all adsorbents. Obviously, increasing the number of adsorbents leads to an increase in the effective adsorbent surface area and then an increase in the adsorption rate of the heavy metal ions.

For this experiment, the $\mathrm{pH}$ value of the chromium and iron solution was adjusted 2 and 4, respectively, the contact time between the contaminated solution and adsorbent was $120 \mathrm{~min}$, 


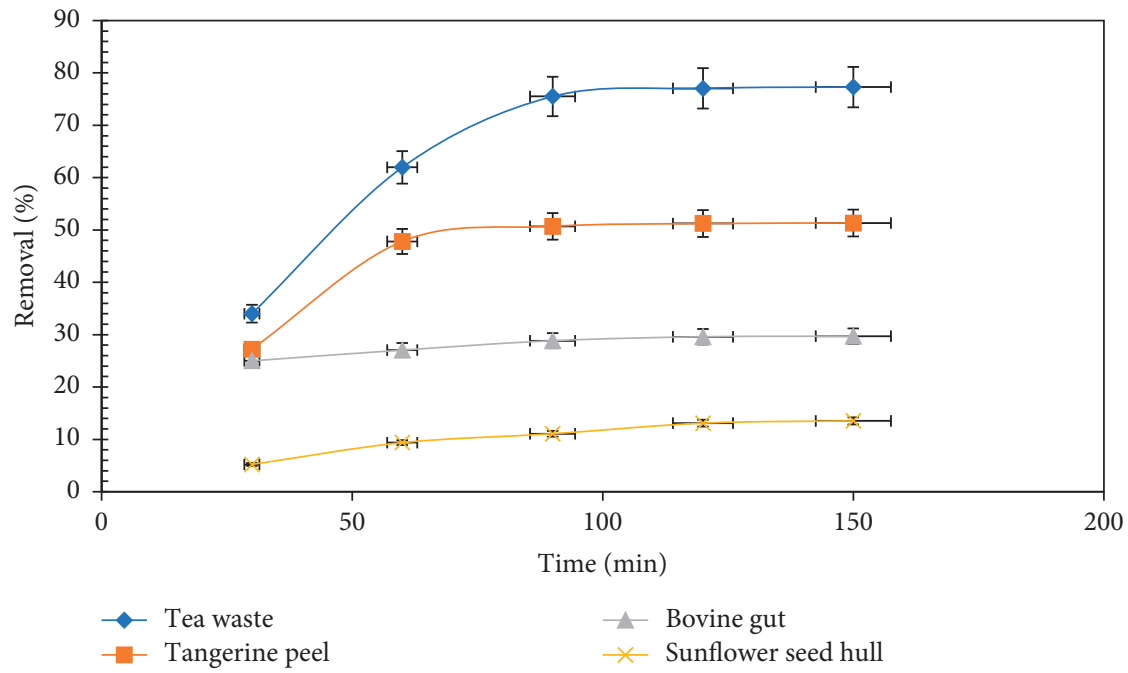

(a)

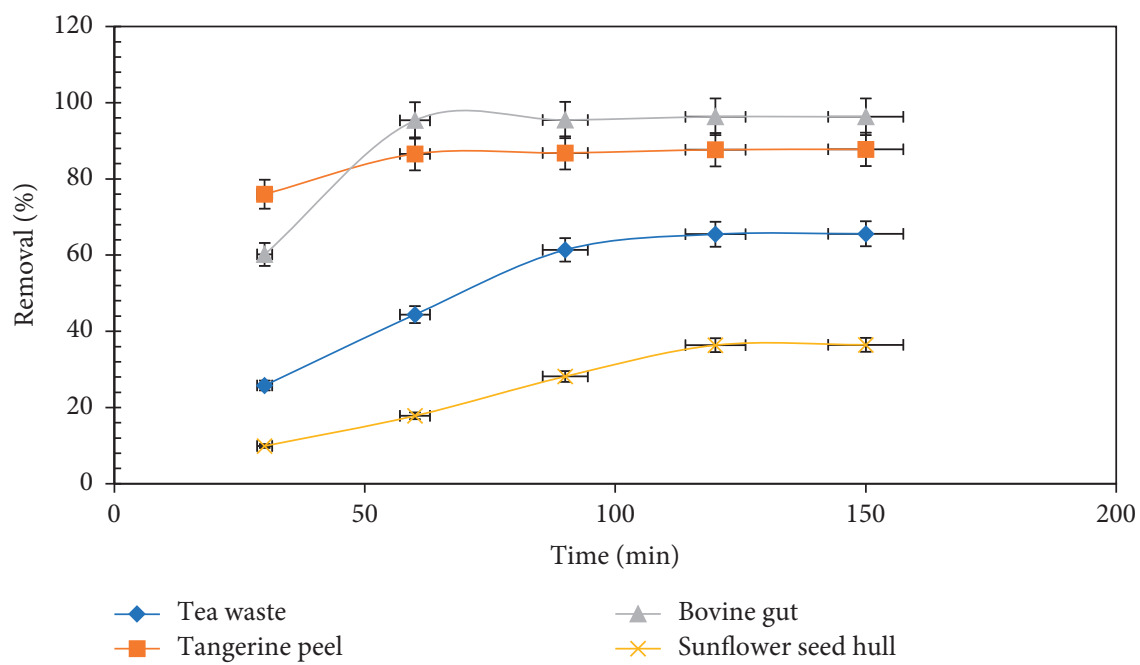

(b)

FIgURE 3: (a) Effect of contact time on chromium adsorption rate. (b) Effect of contact time on iron adsorption rate.

and the initial concentration of metal ions was $100 \mathrm{ppm}$. The results of the adsorbent amount effect on the removal percentages of heavy metals are shown in Figures 4(a)-4(c).

According to the results, we can conclude that the adsorption amount increases with increasing the adsorbent dose. Also, with increasing the amount of adsorbent, the removal rate of metal ions increases due to the enhancement of active sites [58]. Studies by Sharma et al. showed that when the amount of rice husk increases, the removal percentage of metal ions increases $[59,60]$. In some cases, it was found that with increasing the dose of adsorbent after a certain amount, the adsorption rate decreases, which is consistent with the results of the present study. The reason that can be explained for the lack of adsorption of metal ions at higher values than the optimum dose of adsorbent is the overlap of adsorption sites on the adsorbent surface, which leads to a decrease in the adsorption sites, and therefore, this factor is one of the important causes of decreasing the adsorption rate and adsorption rate [16]. Due to the high surface area of the adsorbent, the adsorbent particles are highly reactive, and by increasing the amount of adsorbent in the solution, these particles react with each other instead of eliminating the heavy metal elements, and they come in the form of lumps, and their specific surface area decreases and the adsorption rate of metal ions by these particles is reduced $[7,61]$. The low optimum amount of adsorbent indicates that the studied adsorbent has a good potential for adsorption of contaminants at the operating scale.

Dave et al. and Nigam et al. investigated the effect of adsorbent dose on the removal of chromium ions. Comparing the results of this study, it was observed that with increasing the dose of adsorbent in solution, the percentage of ion removal from the solution increases, but after a certain amount, the percentage of ion removal decreases $[55,56]$.

3.5. Optimal Initial Concentration of Metal Ions in Solution. The adsorption amount of metal ions from aqueous media depends on the initial concentration of these ions in the 


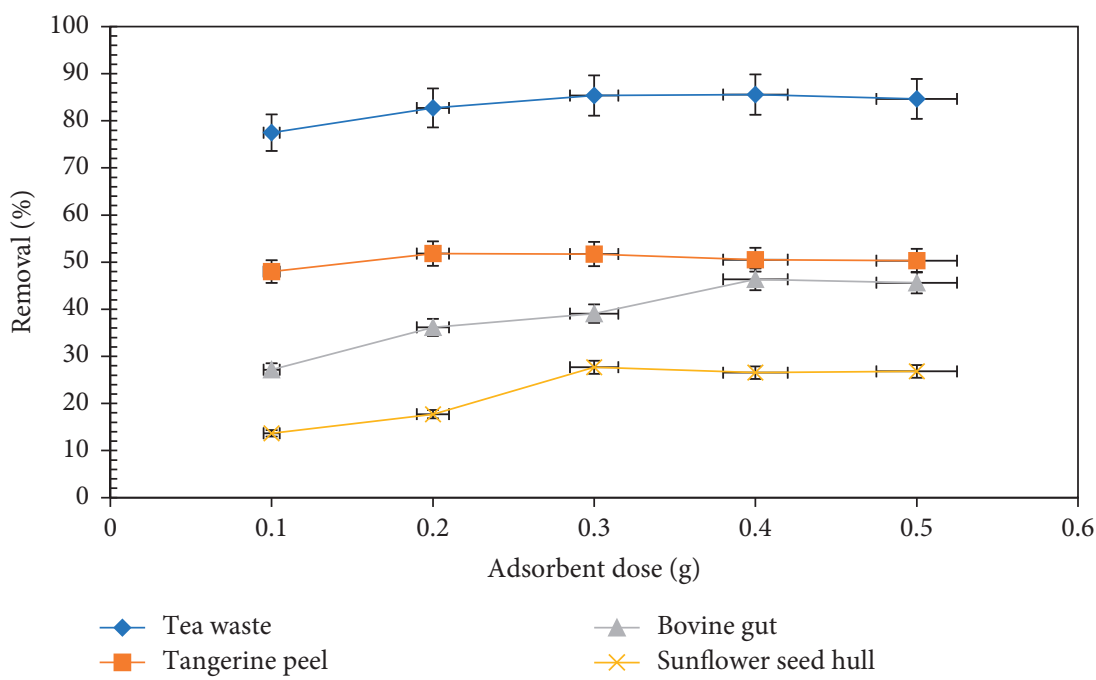

(a)

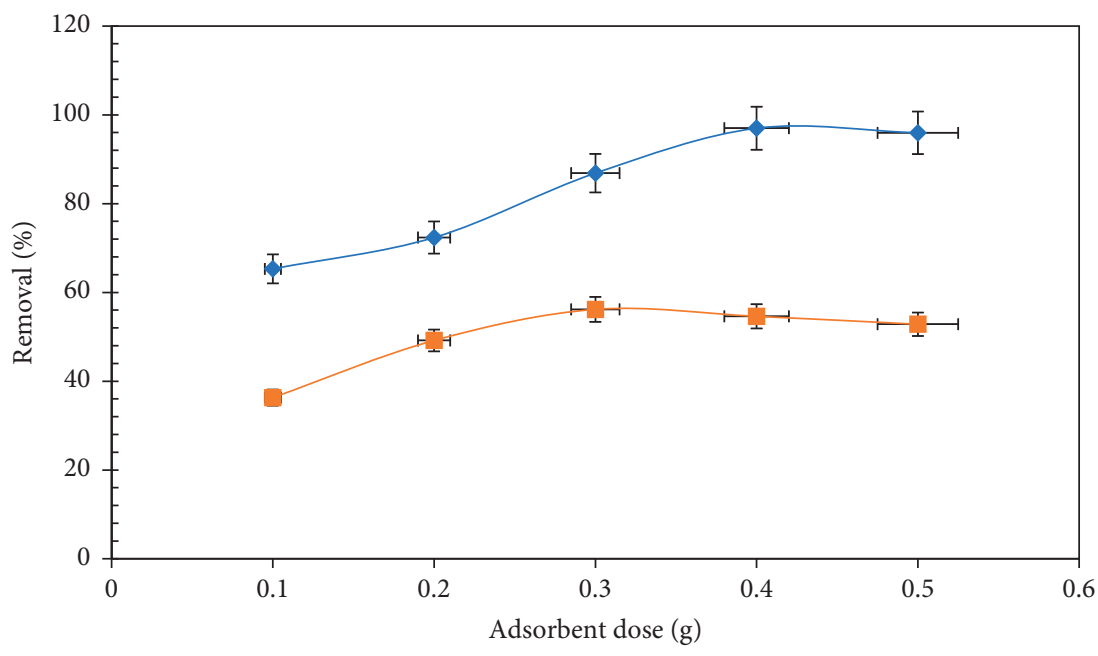

Tea waste

Sunflower seed hull

(b)

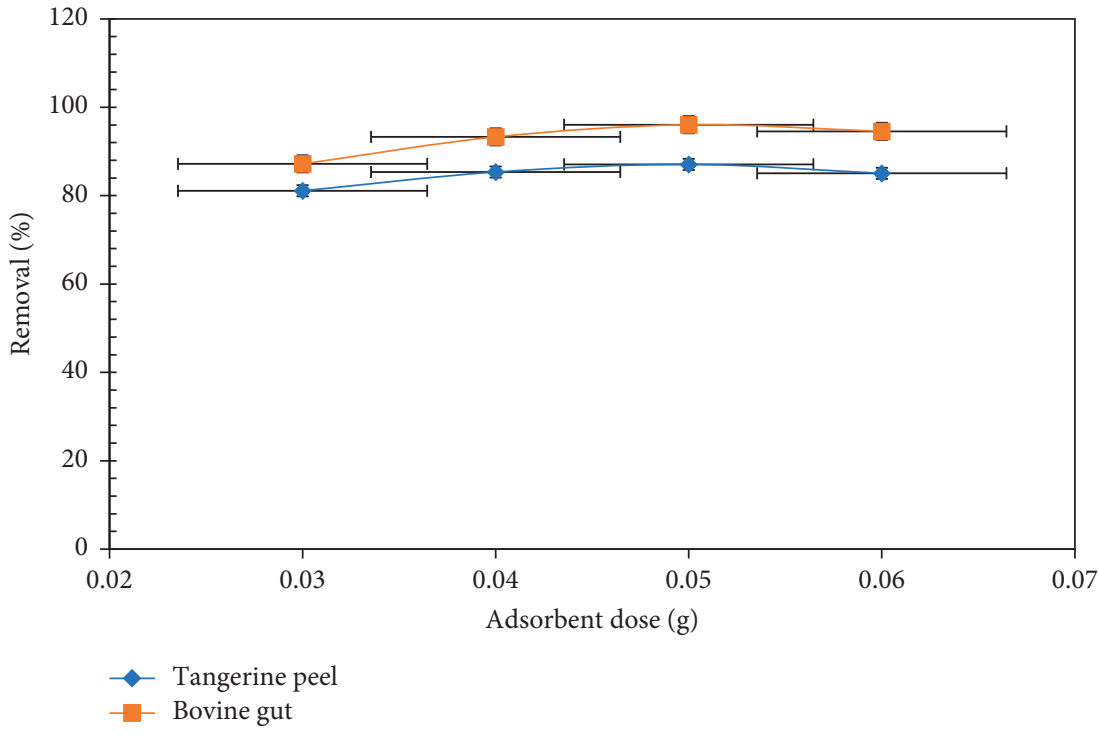

(c)

Figure 4: (a) Effect of adsorbent dose on chromium adsorption rate. (b) Effect of tea waste and sunflower seed hull dose on iron adsorption rate. (c) Effect of tangerine peel and bovine gut dose on iron adsorption rate. 
contaminated solution. In order to obtain the optimum concentration of a solution containing metal ions by keeping other parameters constant, different concentrations of solution were tested, and thus, the optimum initial concentration of solution to remove metal ions by four adsorbents was measured. In the experiment, to determine the initial concentration of heavy metal in the solution, the optimum premeasured values from previous parts were selected. For removal of chromium, the adsorbent amounts for tea waste, bovine gut, tangerine peel, and sunflower seed hull were selected as $0.4 \mathrm{~g}, 0.4 \mathrm{~g}, 0.2 \mathrm{~g}$, and $0.3 \mathrm{~g}$, respectively. Also, for removal of iron ions, the adsorbent amounts for tea waste, bovine gut, tangerine peel, and sunflower seed hull were selected as $0.4 \mathrm{~g}, 0.05 \mathrm{~g}, 0.05 \mathrm{~g}$, and $0.3 \mathrm{~g}$, respectively. The results of this part of the experiments for adsorption of chromium and iron are shown in Figures 5(a) and 5(b), respectively.

The obtained results from Figures 5(a) and 5(b) show that by increasing the initial concentration of metal ions, the adsorption rate first increases and then decreases. Usually, in different adsorbents, if the contaminant concentration increases, the amount of adsorption increases, and the adsorption rate decreases. It can be concluded that with increasing the initial concentration of heavy metal in contaminated solution at a constant adsorbent amount, the ratio of the metal ions in the solution to the adsorbent increases, and as a result, fewer sites are available for adsorption of anions. But the extent of these changes varies for different pollutants [62]. In this experiment, because the adsorbent content is constant, at a low concentration of metal ions, the specific surface area of the adsorbent is high, and the metal ions are able to interact with the available adsorption sites on the adsorbent surface, and thus, the adsorption rate is high. At higher concentrations of heavy metals, the adsorption rate decreases owing to the saturation of adsorption active sites [10]. Also, at lower concentrations, the ratio of the metal ions to the available adsorption sites is low, and thus, the amount of removal will be independent of the initial concentration of ions.

3.6. Equilibrium Isotherm. Adsorption isotherms have a crucial role in predicting the adsorption mechanisms and also breakthrough curves calculating, selectivity, and adsorption capacity $[18,63]$. Isotherm models are commonly used to describe the surface properties, affinity to adsorption, description of experimental adsorption data, and adsorption mechanism. The adsorption equilibrium is achieved when the concentration of metal ions in the interface is in dynamic balance with its concentration in the solution. The adsorption isotherms are based on the principle that each of the active sites is equivalent and the capability of these ions to interact with these sites is independent of occupied adjacent sites [64]. Usually, the adsorption isotherms are the important parameters in describing the quality of adsorbate interaction with adsorbent and are useful to optimize adsorbent consumption. The most general equilibrium model used to understand the mechanism of adsorption isotherms is Langmuir isotherms (monolayer adsorption) and Freundlich (multilayer adsorption).

3.6.1. Langmuir Isotherms. The Langmuir adsorption isotherm is one of the most valid physical laws of adsorption, which is true in many cases of contaminants adsorption and it is used for monolayer adsorption of solutes on surfaces with a limited number of identical adsorption positions. In other words, when the metal ion occupies a site, no other adsorption can occur on this site. This isotherm is defined by the following equation [64]:

$$
\frac{C_{e}}{q_{e}}=\frac{1}{q_{m} b}+\frac{1}{q_{m}} C_{e}
$$

where $q_{m}$ is the maximum adsorption capacity by low-cost adsorbent $(\mathrm{mg} / \mathrm{g}), C_{e}$ is the equilibrium metal ion concentration in the solution $(\mathrm{mg} / \mathrm{L}), q_{e}$ is the equilibrium amount of metal ions uptake on the adsorbent $(\mathrm{mg} / \mathrm{g})$, and $b$ is the equilibrium constant that depends on the amount of adsorbed tendency to the adsorbent. The constant parameters of the equation can be measured by plotting $C_{e} / q_{e}$ versus $C_{e}$ and obtaining the slope $\left(1 / q_{e}\right)$ and intercept (1/ $q_{m} b$ ). The value of $q_{e}$ for each $C_{e}$ is obtained experimentally from the relationship of

$$
q_{e}=\frac{\left(C_{0}-C_{e}\right)}{X_{0}},
$$

where $C_{0}$ and $C_{e}$ are the contaminant concentrations in the inlet and outlet flows, respectively, and $X_{0}$ is the adsorbent dosage, which is defined as the mass of adsorbent mass per unit volume of solution $(\mathrm{g} / \mathrm{L})$. The Langmuir adsorption isotherm was investigated for adsorption of chromium and iron ions by four different adsorbents and the results are shown in Figures 6(a)-6(d) [65].

The equilibrium constant $\left(R_{L}\right)$ is a major property of the Langmuir isotherm which is defined as follows [66]:

$$
R_{L}=\frac{1}{1+b C_{0}},
$$

where $b$ is the Langmuir constant and $C_{0}$ is the initial metal ion concentration. If $R_{L}$ is between zero and one $\left(0<R_{L}<1\right)$, it shows that the Langmuir isotherm model is favorable for adsorption, and if the $R_{L}$ value is greater than one $\left(R_{L}>1\right)$, this isotherm is unfavorable [66]. The regression correlation coefficient $\left(R^{2}\right)$ and equilibrium constant $\left(R_{L}\right)$ values were measured for different adsorbents to adsorption of chromium (Table 4 ). The $R^{2}$ values are $>0.98$ in all cases which indicates their mathematical validation.

Also, Figures 7(a)-7(d) show the results of the Langmuir isotherm analysis on iron ion adsorption by four low-cost adsorbents. The values of $R^{2}$ and $R_{L}$ were measured for validation of experimental results with the Langmuir model. Table 5 illustrates the results of $R^{2}$ and $R_{L}$ data for the adsorption of iron by four low-cost adsorbents. The $R^{2}$ values are $>0.98$ for four adsorbents, which indicates a perfect mathematical fit. 


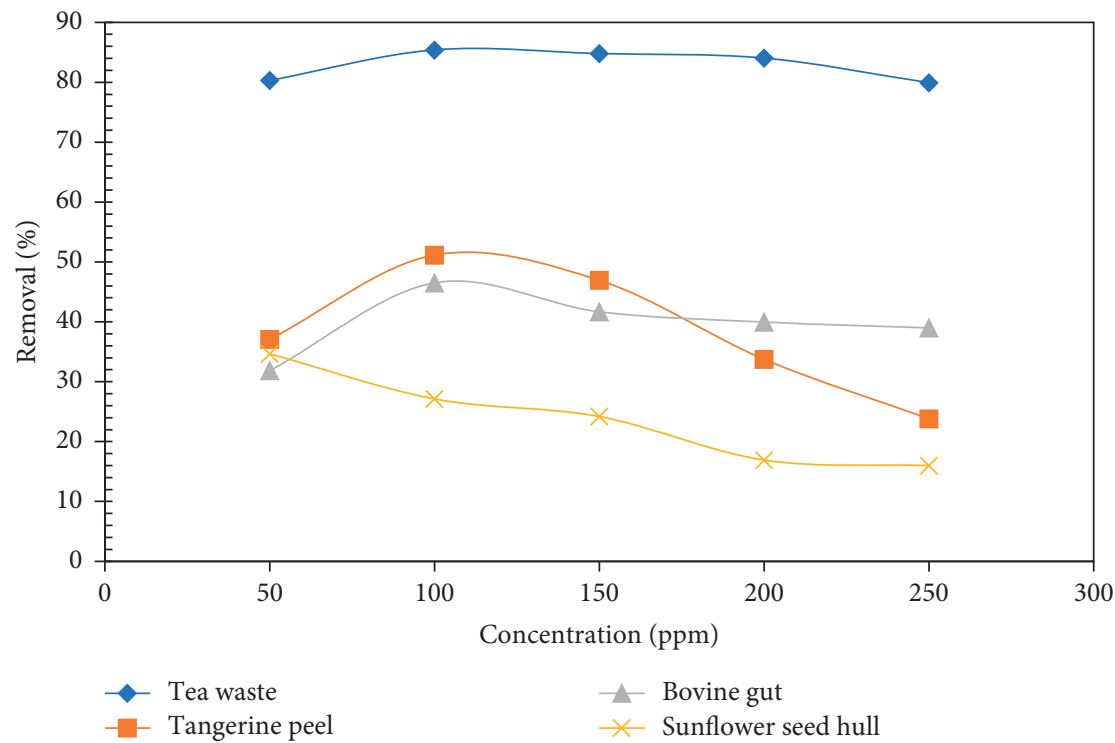

(a)

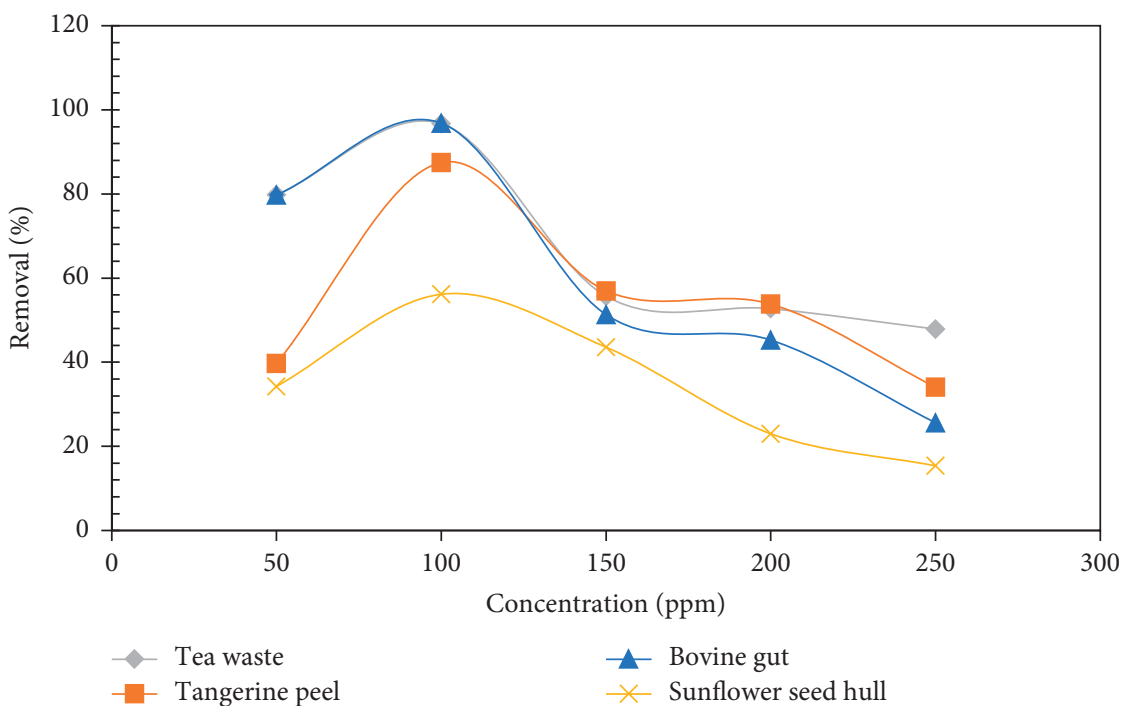

(b)

Figure 5: Effect of initial concentration of metal ions on (a) chromium adsorption rate and (b) iron adsorption rate.

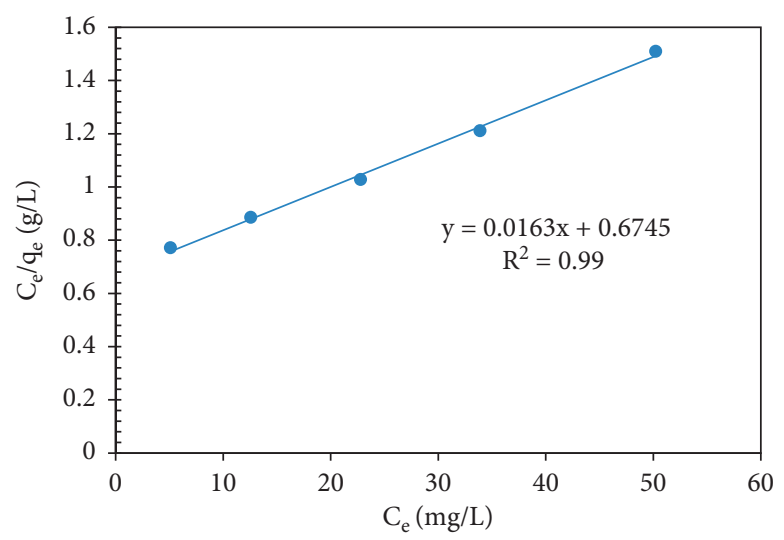

(a)

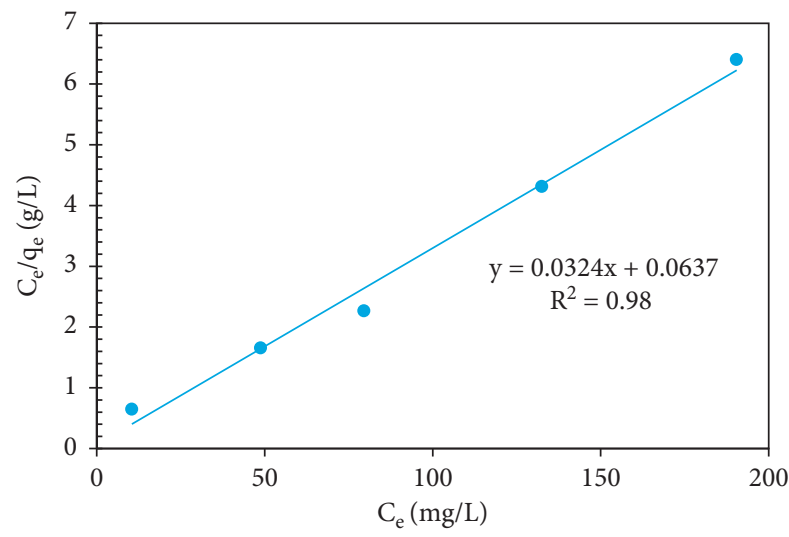

(b)

FIgURE 6: Continued. 


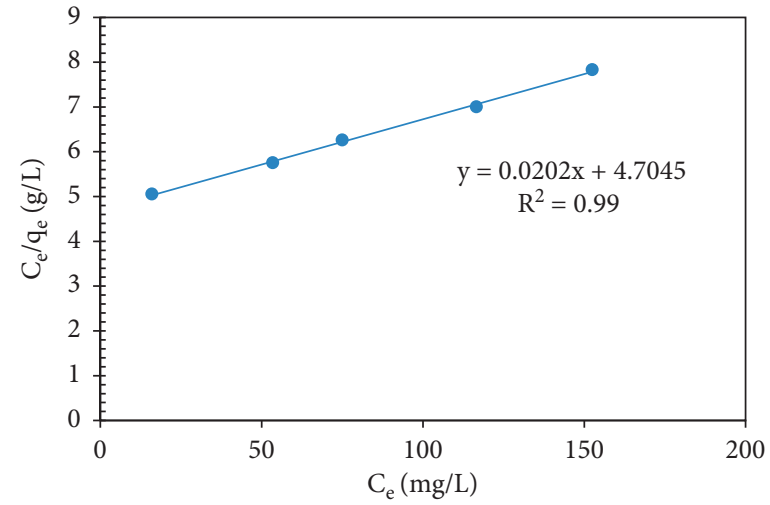

(c)

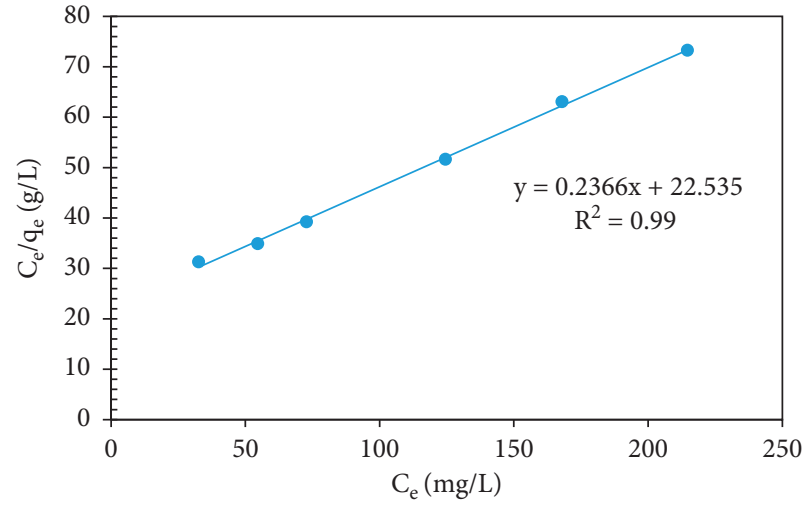

(d)

Figure 6: (a) Chromium adsorption isotherm by tea waste, (b) tangerine peel, (c) bovine gut, and (d) sunflower seed hull based on the Langmuir model.

TABLE 4: Langmuir isotherm parameters for adsorption of chromium ions.

\begin{tabular}{lccrr}
\hline Adsorbents & $Q_{\mathrm{m}}(\mathrm{mg} / \mathrm{g})$ & $b(\mathrm{~L} / \mathrm{mg})$ & $R_{L}$ & $R^{2}$ \\
\hline Tea waste & 61.34 & 0.020 & 0.30 & 0.99 \\
Bovine gut & 49.50 & 0.004 & 0.70 & 0.99 \\
Tangerine peel & 30.86 & 0.500 & 0.02 & 0.98 \\
Sunflower seeds hull & 4.23 & 0.010 & 0.67 & 0.99 \\
\hline
\end{tabular}

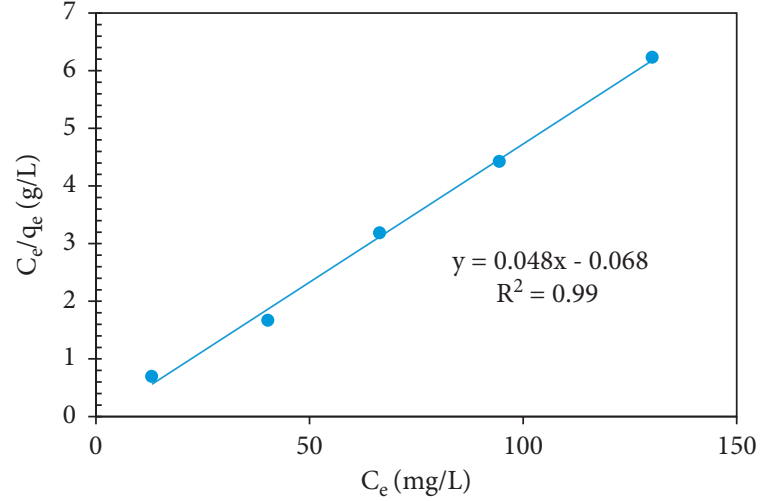

(a)

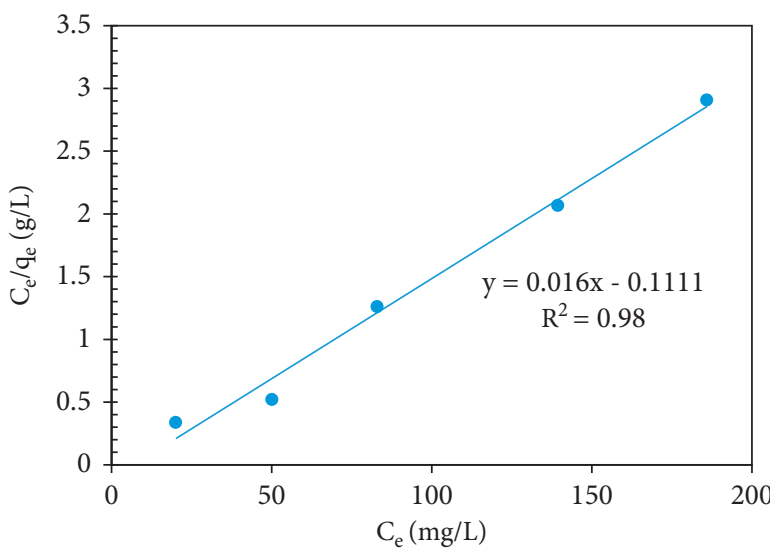

(c)

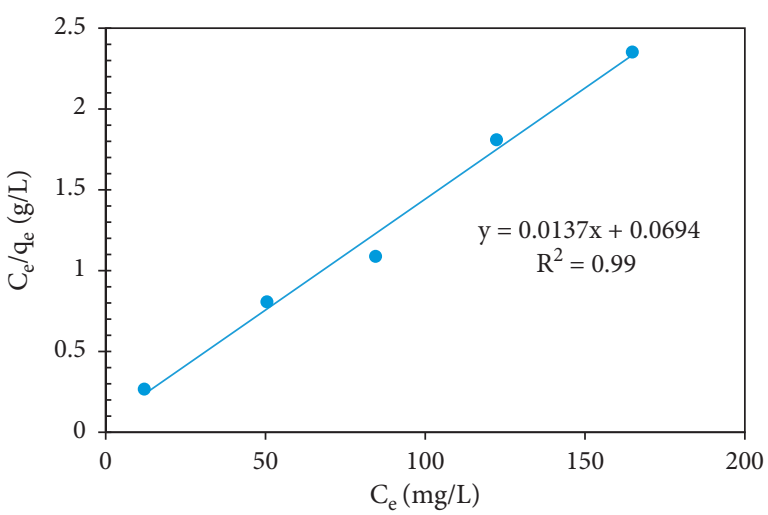

(b)

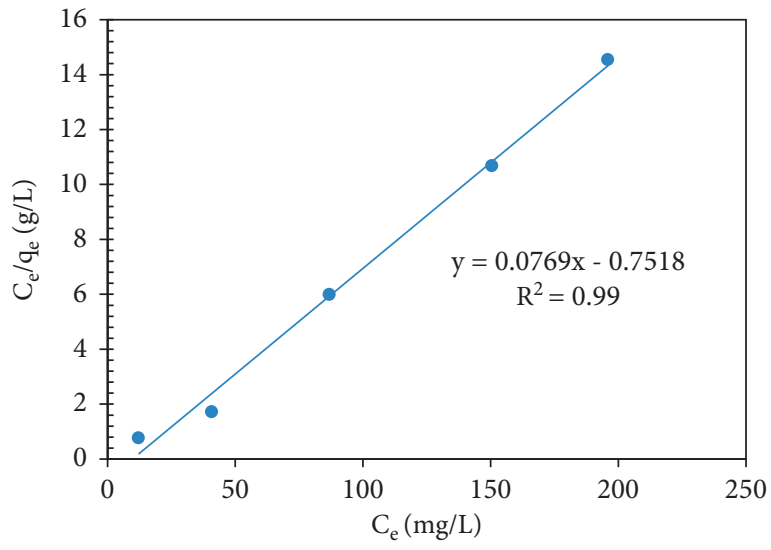

(d)

FIGURE 7: Iron adsorption isotherm by (a) tea waste, (b) tangerine peel, (c) bovine gut, and (d) sunflower seed hull based on the Langmuir model. 
TABLE 5: Langmuir isotherm parameters for adsorption of iron ions.

\begin{tabular}{|c|c|c|c|c|}
\hline Adsorbents & $Q_{m}(\mathrm{mg} / \mathrm{g})$ & $b(\mathrm{~L} / \mathrm{mg})$ & $R_{L}$ & $R^{2}$ \\
\hline Tea waste & 20.83 & 0.700 & 0.014 & 0.99 \\
\hline Bovine gut & 62.50 & 0.144 & 0.065 & 0.98 \\
\hline Tangerine peel & 73.00 & 0.197 & 0.048 & 0.99 \\
\hline Sunflower seeds hull & 13.00 & 0.100 & 0.090 & 0.99 \\
\hline
\end{tabular}

3.6.2. Freundlich Isotherm. The Freundlich isotherm is an empirical relation and applies to the multilayer adsorption on a heterogeneous surface. This isotherm includes the heterogeneity of the adsorption sites and the exponential distribution of these sites and their energy. The Freundlich isotherm is defined as follows [67]:

$$
\log q_{e}=\frac{1}{n_{f}} \log C_{e}+\log K_{f},
$$

where $n_{f}$ and $K_{f}$ are Freundlich constants related to adsorption intensity and adsorption capacity, respectively. If the logarithm of $q_{e}$ is plotted versus the logarithm of $C_{e}$, a line with an intercept of $\log K_{f}$ and a slope of $1 / n_{f}$ will be obtained. The magnitude of $n$ indicates the favorability of adsorbent to adsorption of metal ions, and $n$ values in the range of $n<1$ indicate poor, $1<n<2$ indicates relatively difficult, and $n>2$ indicates the good adsorption. Figures $8(a)-8(d)$ show the results of the Freundlich isotherm analysis on chromium ion adsorption by four different low-cost adsorbents.

Table 6 illustrates the parameters of the Freundlich adsorption isotherm for the adsorption of chromium ions by four various adsorbents. The results of the correlation coefficient $\left(R^{2}\right)$ value (96-98) show that the adsorption process follows the Freundlich model.

Figures 9(a)-9(d) show the results of the Freundlich isotherm analysis on iron ion adsorption by four different low-cost adsorbents.

Also, Table 7 shows the parameters of the Freundlich adsorption isotherm for the adsorption of iron ions by four various adsorbents. The results show that this adsorption model also follows the Freundlich adsorption model and the values of $n_{f}$ show the favor adsorption for the metal ions.

3.7. Kinetics of Adsorption. Another important factor in designing the adsorption system is the adsorption rate, which is controlled by adsorption kinetics and provides suitable information about the adsorption mechanisms and reaction pathways. The adsorption kinetics depends on the physical and chemical properties of the adsorbent, which affects the adsorption mechanism. The adsorption kinetics of chromium and iron ions by low-cost adsorbents were analyzed by using the simulation of two kinetic models including pseudo-first-order and pseudo-secondorder models. These models are used for the mechanism of adsorption and control the reaction rate steps such as mass transfer and chemical reaction progress of kinetics models.
3.7.1. Pseudo-First-Order Model. The simple Lagergren equation is used to investigate the rate of adsorbent interaction [68]. This model defines the rate of metal ions adsorption based on the number of void sites.

$$
\log \left(q_{e}-q_{t}\right)=\log q_{e}-K_{1} t
$$

where $q_{e}$ and $q_{t}$ are the is the adsorption capacity at equilibrium $(\mathrm{mg} / \mathrm{g})$ and time $t(\mathrm{mg} / \mathrm{g})$, respectively, and $K_{1}$ is the pseudo-first-order adsorption rate constant. The value of $K_{1}$ and $q_{e}$ is obtained by linearizing the data by equation (11). The linearity plots of $\log \left(q_{e}-q_{t}\right)$ against time in various concentrations of chromium and iron ions are shown in Figures 10(a) and 10(b), respectively.

In the pseudo-first-order kinetic equation, the parameters associated with the adsorption of chromium and iron are also shown in Tables 8 and 9, respectively.

3.7.2. Pseudo-Second-Order Model. In the pseudo-secondorder model, the adsorption constants can be obtained by using Ho and McKay's chemisorption kinetic model, which is defined as follows [69]:

$$
\frac{t}{q_{t}}=\frac{1}{K_{2} q_{e}^{2}}+\frac{t}{q_{e}},
$$

where $K_{2}$ is the equilibrium rate constant of pseudo-secondorder ( $\mathrm{g} / \mathrm{mg} \mathrm{min}$ ). By plotting the graph of $t$ versus $t / q_{t}$, the value of $K_{2}$ was obtained as the intercept. Figures 11(a) and 11(b) illustrate the linearization of the pseudo-second-order kinetic model data for the adsorption of chromium and iron ions by four different adsorbents, respectively.

Tables 10 and 11 also show the values of the linearization parameters of the pseudo-second-order model, including the correlation coefficient and $K_{2}$.

According to the results obtained from comparing the correlation coefficient of pseudo-first-order and secondorder equations, it was found that the second-order model has better validation with experimental data compared with the pseudo-first-order model, and this model indicates that the filling intensity of adsorption sites is proportional with the square of the number of vacant adsorption sites. The pseudo-second-order kinetic model has been widely used in the study of adsorption kinetics of liquid solutions and to a large extent in justifying the kinetic behavior of adsorption the dyes, herbicides, metal ions, oils, and organic compounds from aqueous solutions and usually has been successful. The pseudo-second-order kinetic model is based on the assumption that the rate-limiting step is chemisorption or chemical sorption and also predicts the adsorption behavior [70, 71]. 


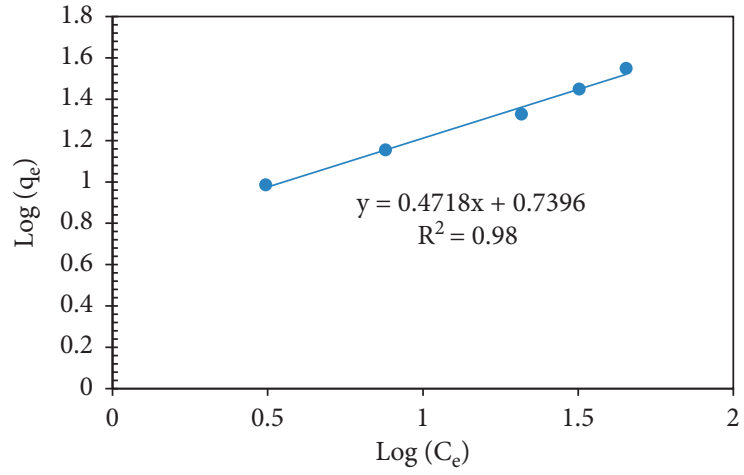

(a)

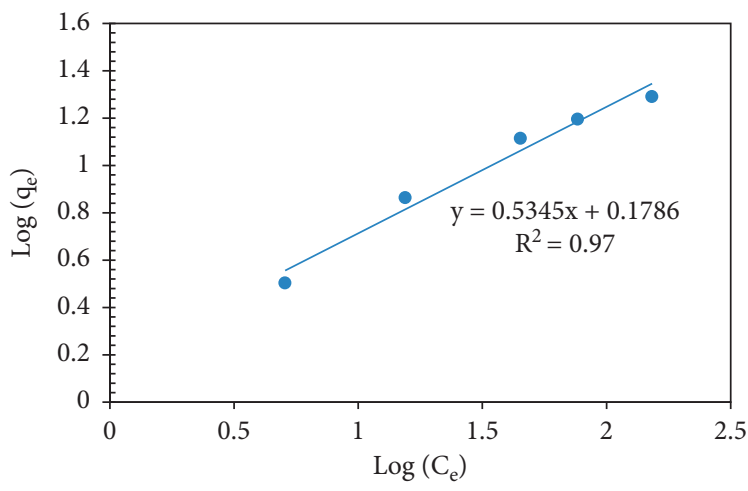

(c)

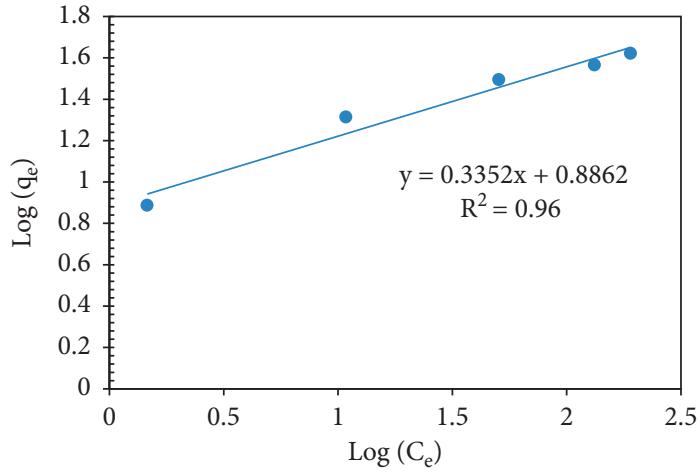

(b)

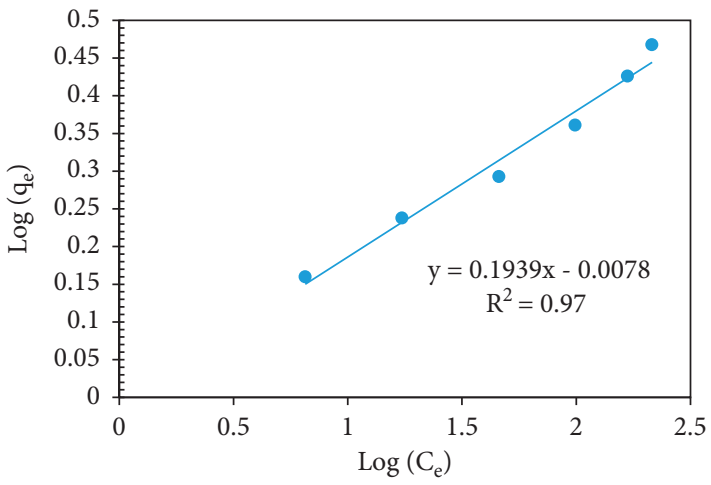

(d)

Figure 8: Chromium adsorption isotherm by (a) tea waste, (b) tangerine peel, (c) bovine gut, and (d) sunflower seed hull based on the Freundlich model.

TABLE 6: Freundlich isotherm parameters for adsorption of chromium ions.

\begin{tabular}{lccr}
\hline Adsorbents & $n$ & $K_{f}(\mathrm{~L} / \mathrm{g})$ & $R^{2}$ \\
\hline Tea waste & 2.10 & 5.49 & 0.98 \\
Bovine gut & 1.87 & 1.50 & 0.97 \\
Tangerine peel & 2.98 & 7.69 & 0.96 \\
Sunflower seeds hull & 5.20 & 1.00 & 0.97 \\
\hline
\end{tabular}

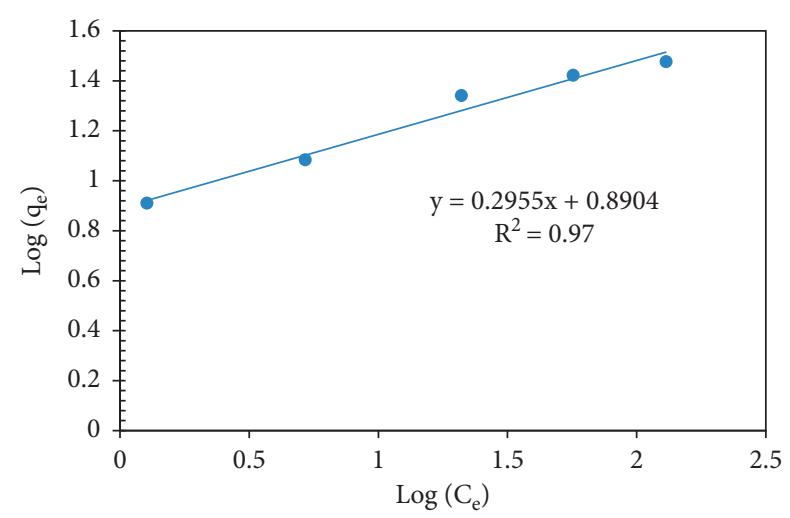

(a)

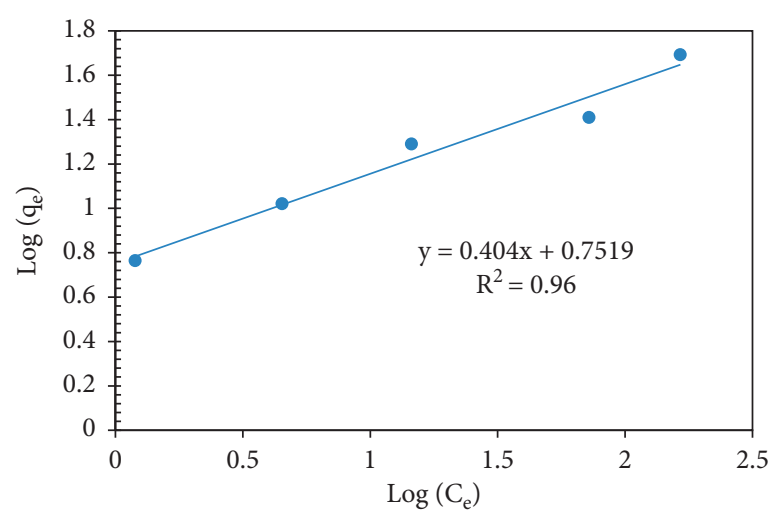

(b)

Figure 9: Continued. 


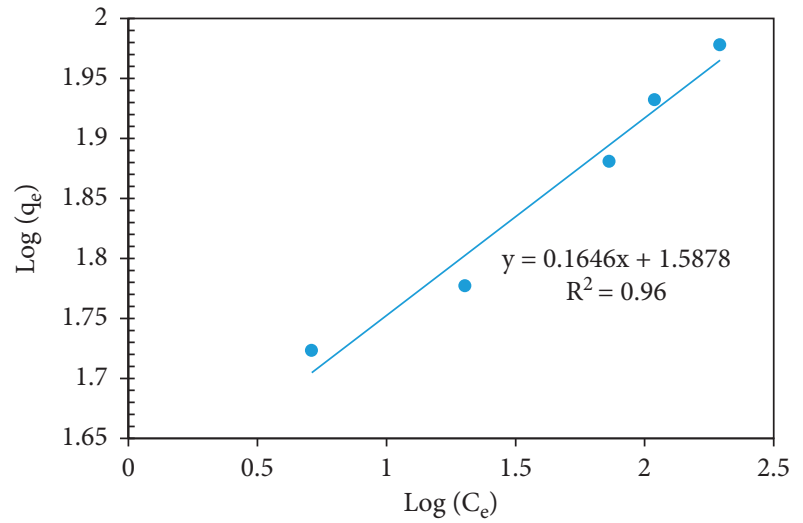

(c)

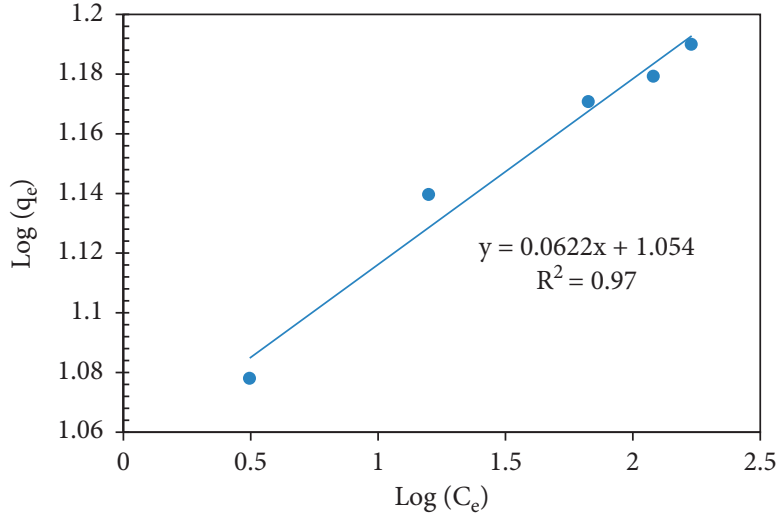

(d)

FiguRE 9: Iron adsorption isotherm by (a) tea waste, (b) tangerine peel, (c) bovine gut, and (d) sunflower seed hull based on the Freundlich model.

TABLE 7: Freundlich isotherm parameters for adsorption of iron ions.

\begin{tabular}{lccc}
\hline Adsorbents & $n$ & $K_{f}(\mathrm{~L} / \mathrm{g})$ & $R^{2}$ \\
\hline Tea waste & 3.38 & 7.77 & 0.97 \\
Bovine gut & 6.10 & 38.70 & 0.98 \\
Tangerine peel & 2.47 & 5.65 & 0.96 \\
Sunflower seeds hull & 16.10 & 11.32 & 0.97 \\
\hline
\end{tabular}

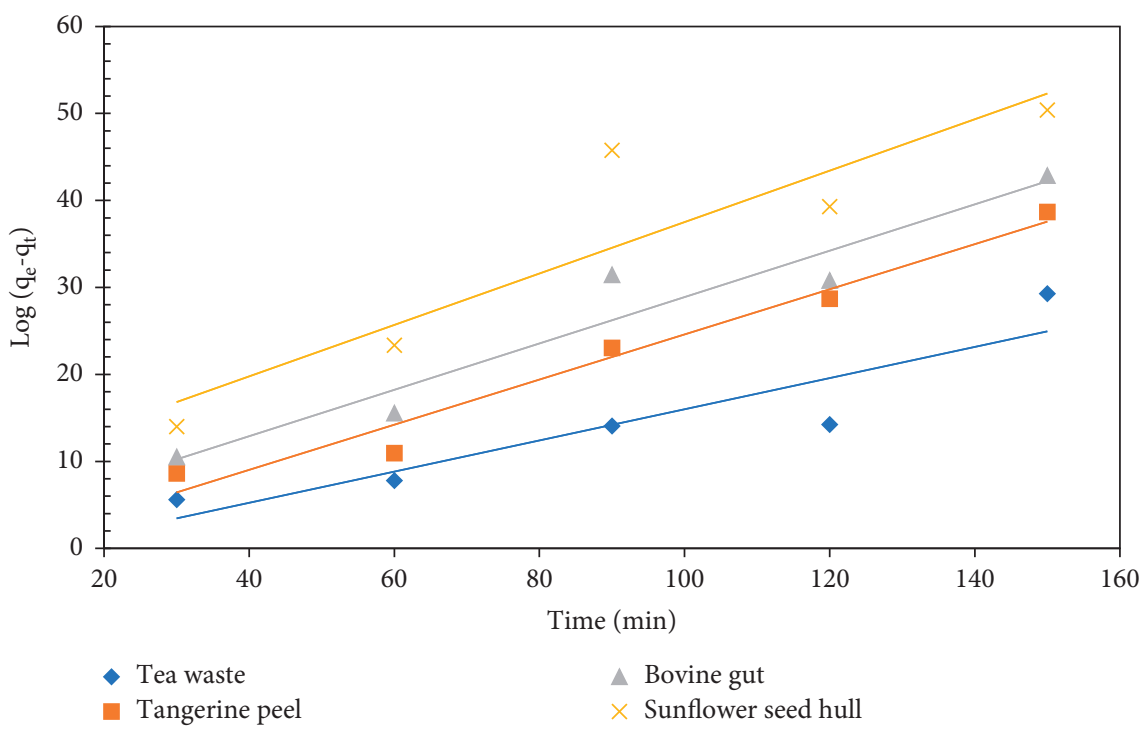

(a)

Figure 10: Continued. 


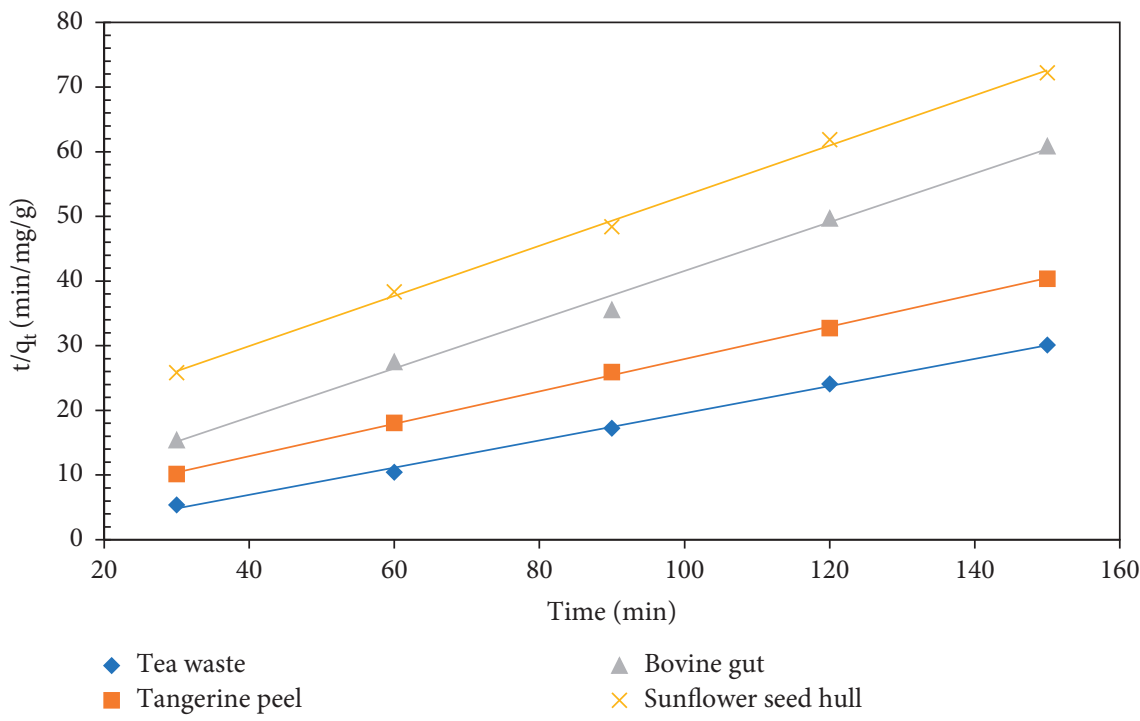

(b)

FIgURe 10: (a) Pseudo-first-order kinetic model in adsorption of chromium ion. (b) Pseudo-first-order kinetic model in adsorption of iron ion.

TABLE 8: Pseudo-first-order kinetic parameters of chromium adsorption.

\begin{tabular}{|c|c|c|c|c|}
\hline Adsorbents & $C(\mathrm{ppm})$ & $Q(\mathrm{mg} / \mathrm{g})$ & $K_{1}(\mathrm{mg} /(\mathrm{g} \cdot \min ))$ & $R^{2}$ \\
\hline Tea waste & 100 & 3.140 & 0.28 & 0.84 \\
\hline Bovine gut & 100 & 0.548 & 0.23 & 0.93 \\
\hline Tangerine peel & 100 & 1.200 & 0.45 & 0.96 \\
\hline Sunflower seeds hull & 50 & 4.680 & 0.46 & 0.83 \\
\hline
\end{tabular}

TAвLE 9: Pseudo-first-order kinetic parameters of iron adsorption.

\begin{tabular}{lcccc}
\hline Adsorbents & $C(\mathrm{ppm})$ & $Q(\mathrm{mg} / \mathrm{g})$ & $K_{1}(\mathrm{mg} /(\mathrm{g} . \mathrm{min}))$ & 0.43 \\
\hline Tea waste & 100 & 0.56 & 0.50 & 0.85 \\
Bovine gut & 100 & 0.52 & 1.44 & 0.97 \\
Tangerine peel & 100 & 0.38 & 0.38 & 0.86 \\
Sunflower seeds hull & 100 & 0.91 & 0.94 \\
\hline
\end{tabular}

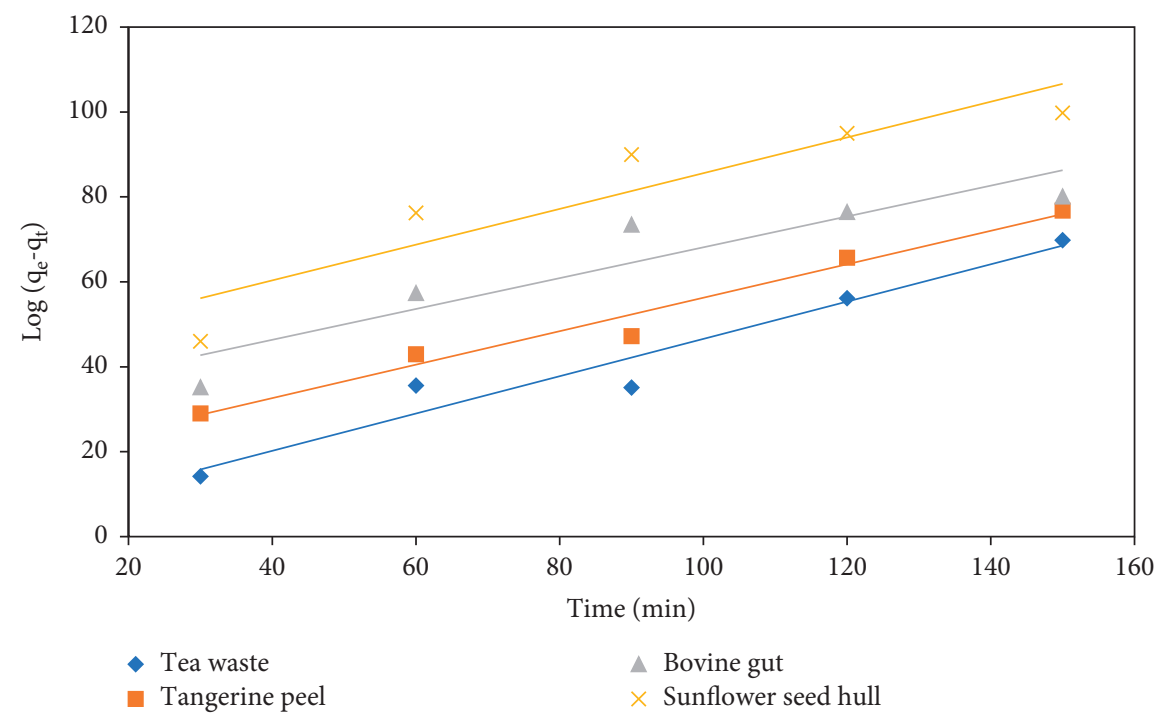

(a)

FIgURE 11: Continued. 


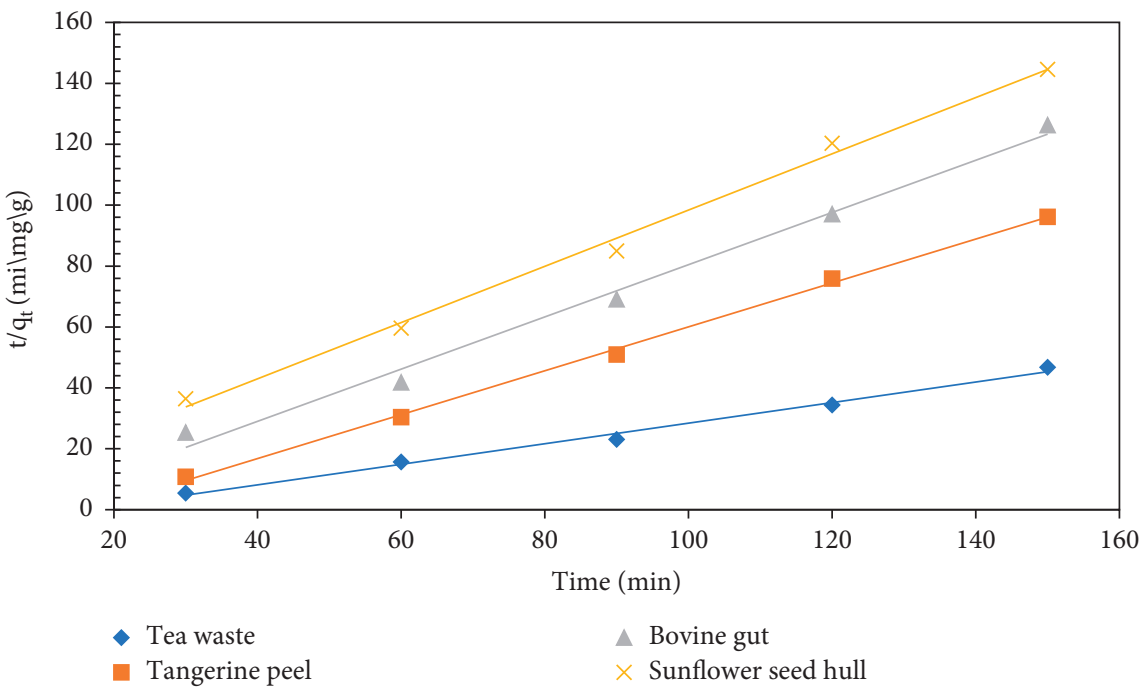

(b)

Figure 11: (a) Pseudo-second-order kinetic model in adsorption of chromium ion and (b) iron ion.

TABle 10: Pseudo-second-order kinetic parameters of chromium adsorption.

\begin{tabular}{lcccc}
\hline Adsorbents & $C(\mathrm{ppm})$ & $Q(\mathrm{mg} / \mathrm{g})$ & $K_{2}(\mathrm{mg} / \mathrm{g} \mathrm{min})$ & $R^{2}$ \\
\hline Tea waste & 100 & 1.66 & 0.610 & 0.99 \\
Bovine gut & 100 & 1.50 & 2.970 & 0.99 \\
Tangerine peel & 100 & 2.60 & 1.150 & 0.99 \\
Sunflower seeds hull & 50 & 3.45 & 0.438 & 0.99 \\
\hline
\end{tabular}

TABLE 11: Pseudo-second-order kinetic parameters of iron adsorption.

\begin{tabular}{|c|c|c|c|c|}
\hline Adsorbents & $C(\mathrm{ppm})$ & $Q(\mathrm{mg} / \mathrm{g})$ & $K_{1}(\mathrm{mg} / \mathrm{g} \min )$ & $R^{2}$ \\
\hline Tea waste & 100 & 1.25 & 0.360 & 0.99 \\
\hline Bovine gut & 100 & 9.70 & 0.052 & 0.99 \\
\hline Tangerine peel & 100 & 8.93 & 0.056 & 0.99 \\
\hline Sunflower seeds hull & 100 & 1.12 & 0.090 & 0.99 \\
\hline
\end{tabular}

\subsection{Characteristics of Waste Tea Adsorbent}

3.8.1. BET Analysis and Porosity Characteristics. Adsorption is a complex process and many parameters are effective in the adsorption process. One of the important and useful factors is the size of the adsorbent pores. The pores' structure and surface chemistry of the adsorbent have a significant impact on the adsorption process. Brunauer-Emmett-Teller (BET) theory is an extended form of the Langmuir theory. This method is used to measure the surface area, volume, and porosity of adsorbents. In this study, surface area, pores volume, and the pores radius of adsorbent before and after adsorption were investigated, which results are shown in Table 12 . The diagrams related to the adsorption and desorption of metal ions by tea waste have been shown in Figures 12(a)-12(c).

The adsorption and desorption graphs for all three adsorbent samples were analyzed, and the results indicated a hysteresis in the graphs. This hysteresis also indicates the existence of mesoporous in the material.
Examination of surface area the pore volume indicated that before adsorption, the sample had the maximum pore volume and surface area, and after adsorption, this value was lower for the chromium sample and much lower for the iron sample. Because the particle size of chromium ions is larger than that of iron ions, the iron ions can easily occupy the tiny cavities [72-74].

3.8.2. FTIR Analysis. The results of Fourier transform infrared (FTIR) spectra for tea waste adsorbent before and after adsorption of chromium and iron ions are shown in Figure 13. The tea waste adsorbent has the best performance compared to the other three adsorbents; therefore, the FTIR test was performed only for this adsorbent. The small bands obtained at $3410 \mathrm{~cm}^{-1}$ and $3412 \mathrm{~cm}^{-1}$ were related to the $\mathrm{O}-\mathrm{H}$ bending that indicated the existence of phenolic and alcohol compounds in the adsorbent structure. The bands at the peaks of $2928 \mathrm{~cm}^{-1}$ and $2929 \mathrm{~cm}^{-1}$ are related to the aliphatic $\mathrm{C}-\mathrm{H}$ vibration 
TABLE 12: BET analysis results of tea waste adsorbent.

\begin{tabular}{lccc}
\hline Tea waste adsorbents & Volume of the cavities $\left(\mathrm{cm}^{3} / \mathrm{g}\right)$ & Surface area $\left(\mathrm{m}^{2} / \mathrm{g}\right)$ & Radius of cavities $(\mathrm{nm})$ \\
\hline Before adsorption & 0.06480 & 0.28220 & 2.44 \\
After adsorption of chromium & 0.05730 & 0.24953 & 2.44 \\
After adsorption of iron & 0.04107 & 0.17880 & 2.44 \\
\hline
\end{tabular}

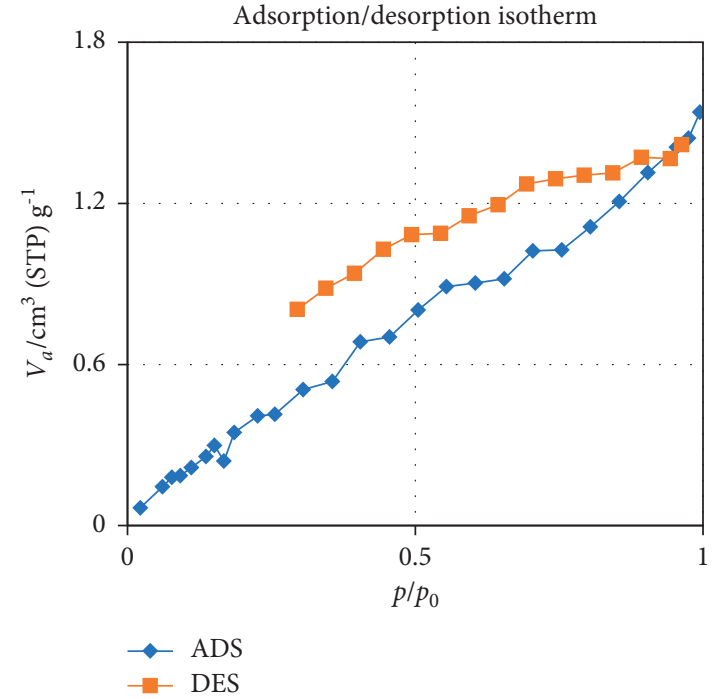

(a)

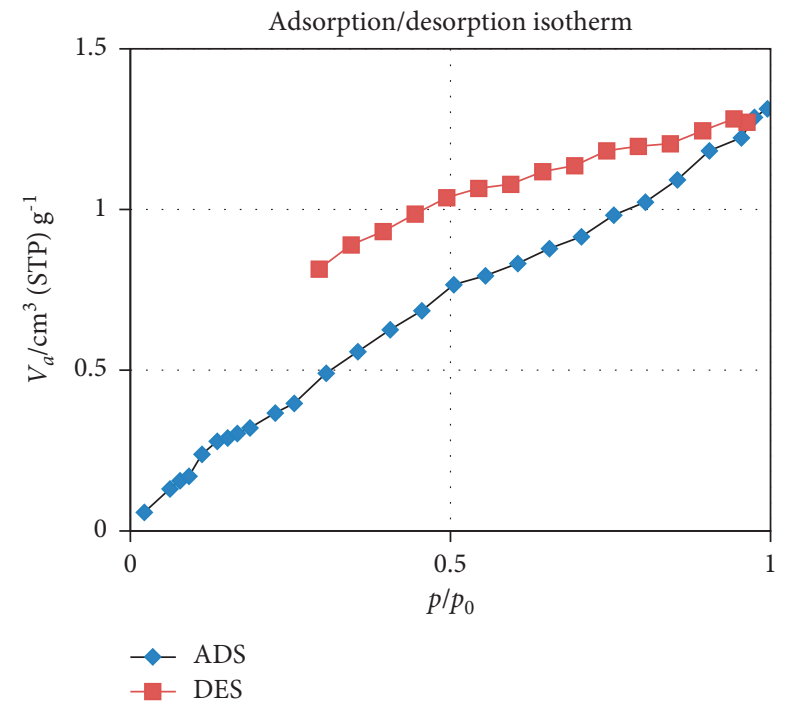

(b)

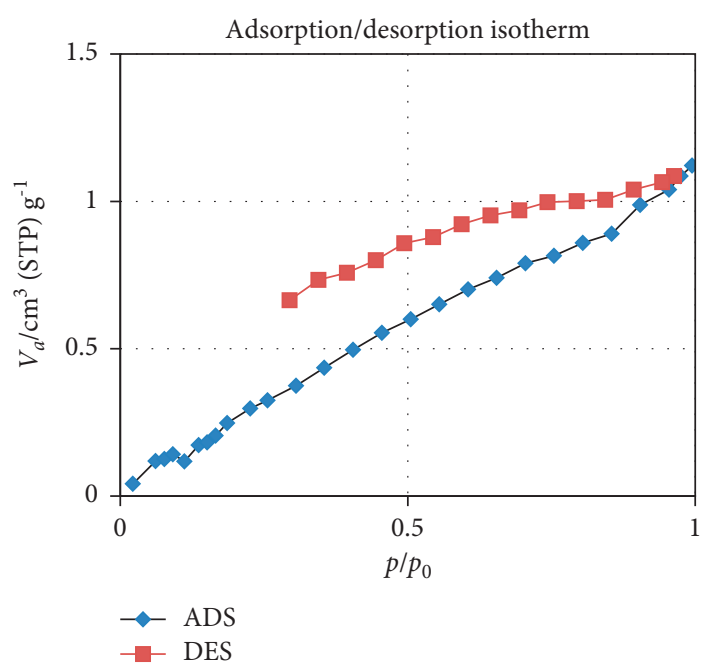

(c)

FIgURE 12: (a) The BET diagrams of adsorption and desorption of the tea waste sample before the adsorption, (b) after the adsorption of chromium ions, and (c) after the adsorption of iron ions.

that represented the contribution of $\mathrm{CH}_{3}$ and $\mathrm{CH}_{2}$ stretching [54]. The peaks of $1638 \mathrm{~cm}^{-1}$ and $1654 \mathrm{~cm}^{-1}$ (which are placed in the range of 1450 to $1680 \mathrm{~cm}^{-1}$ ) are related to the $\mathrm{C}=\mathrm{C}$ stretching vibration of aromatic alkenes and compounds, although the peak of $2928 \mathrm{~cm}^{-1}$ and $2929 \mathrm{~cm}^{-1}$ is more likely to represent alkenes. The bands at the peaks of $1054 \mathrm{~cm}^{-1}$ and $1246 \mathrm{~cm}^{-1}$ indicate the existence of $\mathrm{C}-\mathrm{O}$ bonds [72-77].
3.8.3. SEM Analysis. SEM analysis is among the most common methods to study surface morphology. Figure 14 compares the surface morphology of tea waste before adsorption (Figure 14(a)), after adsorption of chromium ions (Figure 14(b)), and after adsorption of iron ions (Figure 14(c)). Obviously, the change in surface morphology is more significant after the adsorption of chromium ions compared to the iron ion adsorption. 


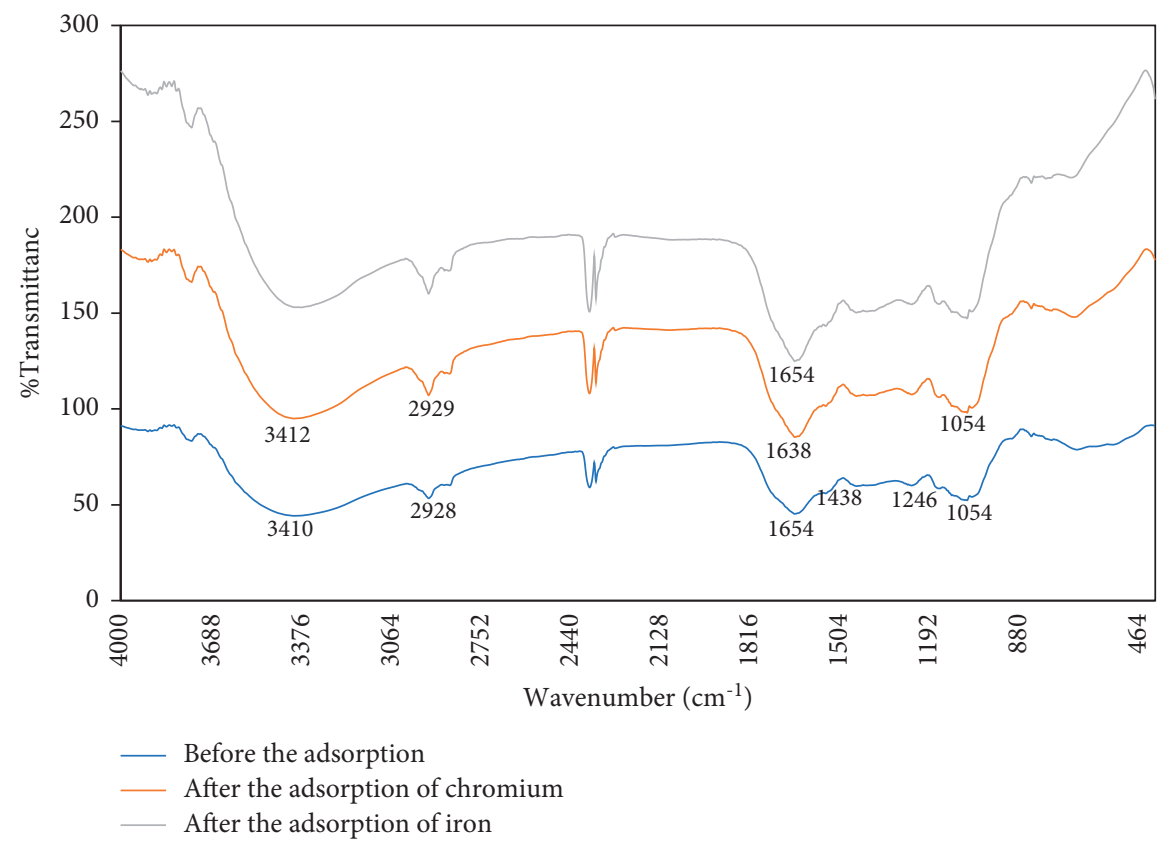

FIGURE 13: FTIR spectrum of tea waste adsorbent.

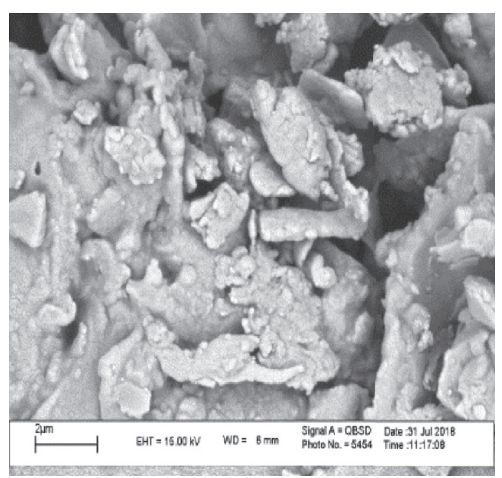

(a)

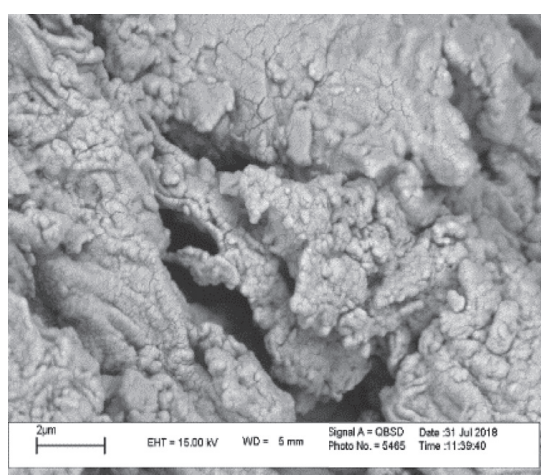

(b)

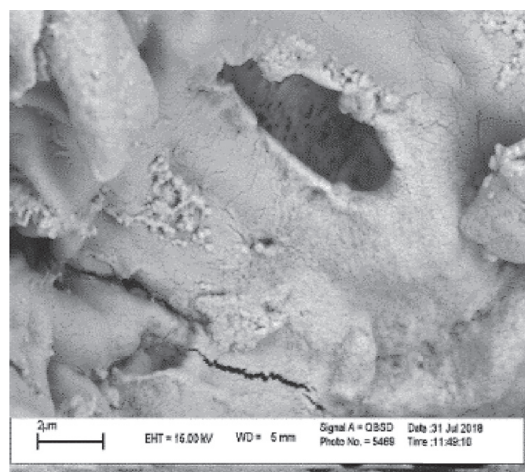

(c)

FIGURE 14: (a) SEM image of tea waste before absorption, (b) after chromium adsorption, and (c) after iron absorption.

\section{Conclusions}

The results showed that the equilibrium time of the adsorption process, as well as the adsorption rate as economic characteristics, is of the utmost importance for the development of water purification technology based on natural adsorbents. Adsorption is greatly affected by the $\mathrm{pH}$ of the solution. In very acidic $\mathrm{pH}$, the adsorption of chromium and iron increases. For example, chromium adsorption at $\mathrm{pH}=2$ was the highest adsorption rate. Adsorption of this metal at $\mathrm{pH}=2$ was associated with tea waste by $85 \%$, tangerine skin by $51 \%$, bovine gut by $46 \%$, and sunflower seed hull by $34 \%$, which decreased gradually with increasing $\mathrm{pH}$. For the adsorption of iron, the adsorbents showed a better adsorption performance at $\mathrm{pH}=4$. Adsorption of iron at this $\mathrm{pH}$ was $96 \%$ for tea waste and bovine gut, $87 \%$ for tangerine skin, and $56 \%$ for sunflower seed hull, which decreased with increasing the $\mathrm{pH}$ value. By increasing the initial metal concentration to $100 \mathrm{ppm}$ (except for the initial concentration of chromium for removal with sunflower seed hull adsorbent to $50 \mathrm{ppm}$ ), the adsorption percentage increases, and then, the adsorption percentage decreases with increasing the initial concentration. Increasing the amount of adsorbent due to the increases in adsorbent contact surface makes the percentage of metal ion removal from the solution increase. By comparing the adsorption isotherm models used in this study, it was observed that the adsorption of metals ions by four different adsorbents follows the Langmuir model more than the Freundlich model, but the process of heavy metal adsorption occurred in both monolayer and multilayer forms. The kinetic investigations indicate that the pseudo-second-order kinetic model is suitable for removing chromium and iron ions from an aqueous solution. Under identical $\mathrm{pH}$ and initial concentration of dissolved metal ion, metal uptake from real effluent is lower than the metal ions removal from synthetic 
effluent, which is likely due to some other impurities in real effluent. By comparing the performance of these four adsorbents in the adsorption of heavy metal ions, it can be concluded that the tea waste adsorbent has higher efficiency for adsorption of iron and chromium ions than the other three adsorbents. In general, it can be concluded that the use of this type of adsorbent for the elimination of heavy metals from polluted water resources according to the advantages of economic, environmental, high adsorption capacity, availability, easy recovery, etc. can be a promising solution.

\section{Data Availability}

The data used to support the findings of this study are included within the article.

\section{Conflicts of Interest}

The authors declare that they have no conflicts of interest.

\section{References}

[1] N. K. Srivastava and C. B. Majumder, "Novel biofiltration methods for the treatment of heavy metals from industrial wastewater," Journal of Hazardous Materials, vol. 151, no. 1, pp. 1-8, 2008.

[2] A. Celik and A. Demirbaş, "Removal of heavy metal ions from aqueous solutions via adsorption onto modified lignin from pulping wastes," Energy Sources, vol. 27, no. 12, pp. 1167-1177, 2005.

[3] M. Friedman and A. C. Waiss Jr, "Mercury uptake by selected agricultural products and by-products," Environmental Science \& Technology, vol. 6, no. 5, pp. 457-458, 1972.

[4] A. H. Mahvi, N. Alavi Nakhjavan, and K. Naddafi, "A survey on detergent removal in Qods township wastewater treatment plant based on activated sludge method," The Horizon of Medical Science, vol. 10, no. 2, pp. 36-41, 2004.

[5] K. Pastircakova, "Determination of trace metal concentrations in ashes from various biomass materials," Energy Education Science and Technology, vol. 13, pp. 97-104, 2004.

[6] S. Morais, F. G. Costa, and M. L. Pereira, "Heavy metals and human health," Environmental Health: Emerging Issues and Practice, vol. 10, pp. 227-246, 2012.

[7] S. M. Mousavi, S. A. Hashemi, A. M. Amani et al., "Pb (II) removal from synthetic wastewater using Kombucha Scoby and graphene oxide/Fe3O4," Physical Chemistry Research, vol. 6, no. 4, pp. 759-771, 2018.

[8] D. Sud, G. Mahajan, and M. Kaur, "Agricultural waste material as potential adsorbent for sequestering heavy metal ions from aqueous solutions-A review," Bioresource Technology, vol. 99, no. 14, pp. 6017-6027, 2008.

[9] M. A. Barakat, "New trends in removing heavy metals from industrial wastewater," Arabian Journal of Chemistry, vol. 4, no. 4, pp. 361-377, 2011.

[10] S. M. Mousavi, S. A. Hashemi, O. Arjmand et al., "Erythrosine adsorption from aqueous solution via decorated graphene oxide with magnetic iron oxide nano particles: kinetic and equilibrium studies," Acta Chimica Slovenica, vol. 65, no. 4, pp. 882-894, 2018.

[11] WHO, Guidelines for Drinking-water Quality, pp. 334-415, WHO, Geneva, Switzerland, 2008.

[12] Y. H. Wang, S. H. Lin, and R. S. Juang, "Removal of heavy metal ions from aqueous solutions using various low-cost adsorbents," Journal of Hazardous Materials, vol. 102, no. 2-3, pp. 291-302, 2003.

[13] T. A. Kurniawan, G. Y. S. Chan, W. H. Lo, and S. Babel, "Physico-chemical treatment techniques for wastewater laden with heavy metals," Chemical Engineering Journal, vol. 118, no. 1-2, pp. 83-98, 2006.

[14] W. Lo, H. Chua, K.-H. Lam, and S.-P. Bi, "A comparative investigation on the biosorption of lead by filamentous fungal biomass," Chemosphere, vol. 39, no. 15, pp. 2723-2736, 1999.

[15] T. A. Kurniawan and S. Babel, "A research study on Cr (VI) removal from contaminated wastewater using low-cost adsorbents and commercial activated carbon," in Proceedings of the Second International Conference. on Energy Technology towards a Clean Environment (RCETE), Phuket, Thailand, February 2003.

[16] S. M. Mousavi, S. A. Hashemi, A. Babapoor et al., "Separation of Ni (II) from industrial wastewater by kombucha scoby as a colony consisted from bacteria and yeast: kinetic and equilibrium studies," Acta Chimica Slovenica, vol. 66, no. 4, pp. 865-873, 2019.

[17] M. A. Hashem, "Adsorption of lead ions from aqueous solution by okra wastes," Physical Science, vol. 2, no. 7, pp. 178-184, 2007.

[18] S. Mohammad beigi, A. Babapoor, V. Maghsoudi, and N. Rajabi, "Batch equilibrium and kinetics studies of Cd (II) ion removal from aqueous solution using porous chitosan hydrogel beads," Iranian Journal of Chemistry and Chemical Engineering, vol. 28, no. 3, pp. 81-89, 2009.

[19] M. Kobya, E. Demirbas, E. Senturk, and M. Ince, “Adsorption of heavy metal ions from aqueous solutions by activated carbon prepared from apricot stone," Bioresource Technology, vol. 96, no. 13, pp. 1518-1521, 2005.

[20] K. Kadirvelu, K. Thamaraiselvi, and C. Namasivayam, "Removal of heavy metals from industrial wastewaters by adsorption onto activated carbon prepared from an agricultural solid waste," Bioresource Technology, vol. 76, no. 1, pp. 63-65, 2001.

[21] A. Kapoor and T. Viraraghavan, "Fungal biosorption-an alternative treatment option for heavy metal bearing wastewaters: a review," Bioresource Technology, vol. 53, no. 3, pp. 195-206, 1995.

[22] U. K. Garg, M. P. Kaur, V. K. Garg, and D. Sud, "Removal of hexavalent chromium from aqueous solution by agricultural waste biomass," Journal of Hazardous Materials, vol. 140, no. 1-2, pp. 60-68, 2007.

[23] Y. Orhan and H. Büyükgüngör, "The removal of heavy metals by using agricultural wastes," Water Science and Technology, vol. 28, no. 2, pp. 247-255, 1993.

[24] B. Yu, Y. Zhang, A. Shukla, Sh. S. Shukla, and K. L. Dorris, "The removal of heavy metal from aqueous solutions by sawdust adsorption-removal of copper," Journal of Hazardous Materials, vol. 80, no. 1-3, pp. 33-42, 2000.

[25] D. Kratochvil, P. Pimentel, and B. Volesky, "Removal of trivalent and hexavalent chromium by seaweed biosorbent," Environmental Science \& Technology, vol. 32, no. 18, pp. 2693-2698, 1998.

[26] F. Pagnanelli, S. Mainelli, F. Vegliò, and L. Toro, "Heavy metal removal by olive pomace: biosorbent characterisation and equilibrium modelling," Chemical Engineering Science, vol. 58, no. 20, pp. 4709-4717, 2003.

[27] E. W. Shin and R. M. Rowell, "Cadmium ion sorption onto lignocellulosic biosorbent modified by sulfonation: the origin of sorption capacity improvement," Chemosphere, vol. 60, no. 8, pp. 1054-1061, 2005. 
[28] B. Volesky and Z. R. Holan, "Biosorption of heavy metals," Biotechnology Progress, vol. 11, no. 3, pp. 235-250, 1995.

[29] N. Ahalya, T. V. Ramachandra, and R. D. Kanamadi, "Biosorption of heavy metals," Research Journal of Chemistry and Environment, vol. 7, no. 4, pp. 71-79, 2003.

[30] E. Marañón and H. Sastre, "Heavy metal removal in packed beds using apple wastes," Bioresource Technology, vol. 38, no. 1, pp. 39-43, 1991.

[31] P. D. Johnson, M. A. Watson, J. Brown, and I. A. Jefcoat, "Peanut hull pellets as a single use sorbent for the capture of $\mathrm{Cu}$ (II) from wastewater," Waste Management, vol. 22, no. 5, pp. 471-480, 2002.

[32] K. S. Low, C. K. Lee, and A. Y. Ng, "Column study on the sorption of $\mathrm{Cr}(\mathrm{VI})$ using quaternized rice hulls," Bioresource Technology, vol. 68, no. 2, pp. 205-208, 1999.

[33] G. Cimino, A. Passerini, and G. Toscano, "Removal of toxic cations and Cr (VI) from aqueous solution by hazelnut shell," Water Research, vol. 34, no. 11, pp. 2955-2962, 2000.

[34] S. Babel and T. A. Kurniawan, "Low-cost adsorbents for heavy metals uptake from contaminated water: a review," Journal of Hazardous Materials, vol. 97, no. 1-3, pp. 219-243, 2003.

[35] B. Amarasinghe and R. A. Williams, "Tea waste as a low cost adsorbent for the removal of $\mathrm{Cu}$ and $\mathrm{Pb}$ from wastewater," Chemical Engineering Journal, vol. 132, no. 1-3, pp. 299-309, 2007.

[36] H. Aydın, Y. Bulut, and Ç. Yerlikaya, "Removal of copper (II) from aqueous solution by adsorption onto low-cost adsorbents," Journal of Environmental Management, vol. 87, no. 1, pp. 37-45, 2008.

[37] V. Basumatary, R. Saikia, R. Narzari et al., "Tea factory waste as a feedstock for thermo-chemical conversion to biofuel and biomaterial," Materials Today Proceedings, vol. 5, no. 11, pp. 23413-23422, 2018.

[38] F.-L. Pua, M. S. Subari, L.-W. Ean, and S. G. Krishnan, "Characterization of biomass fuel pellets made from Malaysia tea waste and oil palm empty fruit bunch," Materials Today Proceedings, vol. 31, pp. 187-190, 2020.

[39] P. S. Katha, Z. Ahmed, R. Alam, B. Saha, A. Acharjee, and M. S. Rahman, "Efficiency analysis of eggshell and tea waste as Low cost adsorbents for Cr removal from wastewater sample," South African Journal of Chemical Engineering, vol. 37, 2021.

[40] S. Abdeltaif, K. SirElkhatim, and A. Hassan, "Estimation of phenolic and flavonoid compounds and antioxidant activity of spent coffee and black tea (processing) waste for potential recovery and reuse in Sudan," Recycling, vol. 3, no. 2, p. 27, 2018.

[41] A. P. M. Belo, C. M. A. Morgado, E. R. B. d. Souza, T. Ogata, C. C. d. O. Pereira, and L. C. Cunha Junior, "Comparative and organic analysis and characterization of varieties of tangerines," Scientia Horticulturae, vol. 240, pp. 102-108, 2018.

[42] A. El Barnossi, F. Moussaid, and A. I. Housseini, “Tangerine, banana and pomegranate peels valorisation for sustainable environment: a review," Biotechnology Reports, vol. 29, Article ID e00574, 2020.

[43] K. Xiong and Y. Chen, "Supercritical carbon dioxide extraction of essential oil from tangerine peel: experimental optimization and kinetics modelling," Chemical Engineering Research and Design, vol. 164, pp. 412-423, 2020.

[44] Š Abdić, M. Memić, E. Šabanović, J. Sulejmanović, and S. Begić, "Adsorptive removal of eight heavy metals from aqueous solution by unmodified and modified agricultural waste: tangerine peel," International journal of Environmental Science and Technology, vol. 15, no. 12, pp. 2511-2518, 2018.
[45] X.-R. Jiang, H.-J. Zhang, J. Wang et al., "Effect of dried tangerine peel extract supplementation on the growth performance and antioxidant status of broiler chicks," Italian Journal of Animal Science, vol. 15, no. 4, pp. 642-648, 2016.

[46] R. V. de Carvalho, T. C. de Abreu, and C. Romanel, "Biogas generation potential from anaerobic digestion of "Ponkan" and "Montenegrin" Tangerine peel waste," Revista Eletrônica em Gestão, Educação e Tecnologia Ambiental, vol. 24, p. 24, 2020.

[47] X. F. Qin, B. Pu, and J. P. Wang, "Ultrasonic extraction of limonoids from orange peel," Food Science and Technology, vol. 9, 2011.

[48] G. B. Oguntimein and T. Duwane, "The potential use of acid treated dried sunflower seed hull as a biosorbent for the removal of textile effluent dye from aqueous solution," Research Inventy: International Journal of Engineering Science, vol. 4, no. 7, pp. 21-30, 2014.

[49] S. Stankovic, T. Sostaric, M. Bugarcic, A. Janicijevic, K. Pantovic-Spajic, and Z. Lopicic, "Adsorption of $\mathrm{Cu}$ (II) ions from synthetic solution by sunflower seed husks," Acta Periodica Technologica, vol. 50, pp. 268-277, 2019.

[50] A. I. Casoni, V. S. Gutierrez, and M. A. Volpe, "Conversion of sunflower seed hulls, waste from edible oil production, into valuable products," Journal of Environmental Chemical Engineering, vol. 7, no. 1, Article ID 102893, 2019.

[51] A. Demirbas, "Heavy metal adsorption onto agro-based waste materials: a review," Journal of Hazardous Materials, vol. 157, no. 2-3, pp. 220-229, 2008.

[52] S. J. Park and W. Y. Jung, "Removal of chromium by activated carbon fibers plated with copper metal," Carbon Letters, vol. 2, no. 1, pp. 15-21, 2001.

[53] E. Pehlivan and T. Altun, "Biosorption of chromium (VI) ion from aqueous solutions using walnut, hazelnut and almond shell," Journal of Hazardous Materials, vol. 155, no. 1-2, pp. 378-384, 2008.

[54] M. E. Argun, S. Dursun, C. Ozdemir, and M. Karatas, "Heavy metal adsorption by modified oak sawdust: thermodynamics and kinetics," Journal of Hazardous Materials, vol. 141, no. 1, pp. 77-85, 2007.

[55] P. N. Dave, N. Pandey, and H. Thomas, Adsorption of Cr (VI) from Aqueous Solutions on Tea Waste and Coconut Husk, NISCAIR-CSIR, New Delhi, India, 2012.

[56] M. Nigam, S. Rajoriya, S. Rani Singh, and P. Kumar, “Adsorption of $\mathrm{Cr}$ (VI) ion from tannery wastewater on tea waste: kinetics, equilibrium and thermodynamics studies," Journal of Environmental Chemical Engineering, vol. 7, no. 3, Article ID 103188, 2019.

[57] M. H. Kalavathy and L. R. Miranda, "Comparison of copper adsorption from aqueous solution using modified and unmodified Hevea brasiliensis saw dust," Desalination, vol. 255, no. 1-3, pp. 165-174, 2010.

[58] K. Selvi, S. Pattabhi, and K. Kadirvelu, "Removal of Cr (VI) from aqueous solution by adsorption onto activated carbon," Bioresource Technology, vol. 80, no. 1, pp. 87-89, 2001.

[59] N. Sharma, J. Singh, and A. Sharma, "Removal of Zn (II) ions from aqueous solution using rice (Oryza sativa) husk in a sequential bed adsorption column," International Journal of Environmental Technology and Management, vol. 12, no. 2-4, pp. 333-342, 2010.

[60] A. Elham, H. Tavallali, and M. Hagshenas, "Removal of Zn (II) and $\mathrm{Pb}$ (II) ions using rice husk in food industrial wastewater," Journal of Applied Sciences \& Environmental Management, vol. 14, no. 4, 2010. 
[61] A. Rahmani, H. Z. Mousavi, and M. Fazli, "Effect of nanostructure alumina on adsorption of heavy metals," Desalination, vol. 253, no. 1-3, pp. 94-100, 2010.

[62] S. A. Dastgheib, T. Karanfil, and W. Cheng, "Tailoring activated carbons for enhanced removal of natural organic matter from natural waters," Carbon, vol. 42, no. 3, pp. 547-557, 2004.

[63] B. K. Kaul, "Correlation and prediction of adsorption isotherm data for pure and mixed gases," Industrial and Engineering Chemistry Process Design and Development, vol. 23, no. 4, pp. 711-716, 1984.

[64] I. Langmuir, "The adsorption of gases on plane surfaces of glass, mica and platinum," Journal of the American Chemical Society, vol. 40, no. 9, pp. 1361-1403, 1918.

[65] M. Ajmal, R. A. Rao, R. Ahmad, and J. Ahmad, "Dsorption studies on Citrus reticulata (fruit peel of orange): removal and recovery of $\mathrm{Ni}$ (II) from electroplating wastewater," Journal of Hazardous Materials, vol. 79, no. 1-2, pp. 117-131, 2000.

[66] Y. S. Ho, J. F. Porter, and G. McKay, "Equilibrium isotherm studies for the sorption of divalent metal ions onto peat: copper, nickel and lead single component systems," Water, Air, and Soil Pollution, vol. 141, no. 1-4, pp. 1-33, 2002.

[67] H. Freundlich, Colloid \& Capillary Chemistry, Methuen \& Co. Ltd, London, UK, 1926.

[68] S. Lagergren, Kungliga svenska vetenskapsakademiens, vol. 24, no. 4, pp. 1-39, 1898.

[69] Y. S. Ho and G. McKay, "Pseudo-second order model for sorption processes," Process Biochemistry, vol. 34, no. 5, pp. 451-465, 1999.

[70] C. S. Zhu, L. P. Wang, and W. B. Chen, "Removal of Cu (II) from aqueous solution by agricultural by-product: peanut hull," Journal of Hazardous Materials, vol. 168, no. 2-3, pp. 739-746, 2009.

[71] X. S. Wang, Y. Li, L. P. Huang, and J. Chen, "Adsorption of Cr (VI) from aqueous solutions by Staphylococcus aureus biomass," Clean - Soil, Air, Water, vol. 38, no. 5-6, pp. 500-505, 2010.

[72] B. N. Kuznetsov, N. V. Chesnokov, and N. M. Mikova, "Porous carbon fibers from copper-substituted plant biomass materials," in Proceedings of the Fifth Biomass Conference of the America, Arlington, VA, USA, March 2010.

[73] N. Asim, M. H. Amin, N. A. Samsudin et al., "Development of effective and sustainable adsorbent biomaterial from an agricultural waste material: $\mathrm{Cu}(\mathrm{II})$ removal," Materials Chemistry and Physics, vol. 249, Article ID 123128, 2020.

[74] R. B. Gapusan and M. D. L. Balela, "Adsorption of anionic methyl orange dye and lead(II) heavy metal ion by polyaniline-kapok fiber nanocomposite," Materials Chemistry and Physics, vol. 243, Article ID 122682, 2012.

[75] A. Hamed Mashhadzadeh, M. Fathalian, M. Ghorbanzadeh Ahangari, and M. H. Shahavi, "DFT study of Ni, Cu, Cd and Ag heavy metal atom adsorption onto the surface of the zincoxide nanotube and zinc-oxide graphene-like structure," Materials Chemistry and Physics, vol. 220, pp. 366-373, 2018.

[76] I. Loulidi, F. Boukhlifi, M. Ouchabi et al., "Assessment of untreated coffee wastes for the removal of chromium (VI) from aqueous medium," International Journal of Chemical Engineering, vol. 2021, Article ID 9977817, 11 pages, 2021.

[77] B. Kavita and H. Keharia, "Biosorption potential of trichoderma gamsii biomass for removal of $\mathrm{Cr}(\mathrm{VI})$ from electroplating industrial effluent," International Journal of Chemical Engineering, vol. 2012, Article ID 305462, 7 pages, 2012. 